\title{
A novel particle-filled Carbon-Fibre Reinforced Polymer model composite tailored for the application of Digital Volume Correlation and Computed Tomography
}

\author{
E. Schöberl ${ }^{1}$, C. Breite ${ }^{2}$, S. Rosini ${ }^{1}$, Y. Swolfs ${ }^{2}$, M. N. Mavrogordato ${ }^{1}$, I. Sinclair ${ }^{1}$, S. M. Spearing ${ }^{1}$ \\ ${ }^{1}$ Engineering Materials, Faculty of Engineering and Physical Sciences, University of Southampton, \\ Southampton SO17 1BJ, UK \\ ${ }^{2}$ Department of Materials Engineering, KU Leuven, Kasteelpark Arenberg 44 box 2450, 3001 Leuven, \\ Belgium
}

Keywords: Carbon-Fibre Reinforced Polymers (CFRPs), Particles, Microstructures, Micromechanics, Micro-focus Computed Tomography $(\mu \mathrm{CT})$, Synchrotron Radiation Computed Tomography (SRCT), Digital Volume Correlation (DVC), Strain mapping

\begin{abstract}
This paper presents the development of novel Carbon-Fibre Reinforced Polymer (CFRP) laminates, tailored for the application of Digital Volume Correlation (DVC) and Computed Tomography (CT) to experimental mechanics analyses of these materials. Analogous to surface-based Digital Image Correlation (DIC), DVC is a relatively novel volumetric method that utilizes CT data to quantify internal threedimensional (3D) displacements and implicit strain fields. The highly anisotropic and somewhat regular/self-similar microstructures found in well-aligned unidirectional (UD) materials at high fibre volume fractions are intrinsically challenging for DVC, especially along the fibre direction at microstructural length-scales on the order of a few fibre diameters. To permit the application of DVC to displacement and/or strain measurements parallel to the fibre orientation, the matrix was doped with a sparse population of sub-micrometre particles to act as displacement trackers (i.e. fiducial markers). Barium titanate particles ( $400 \mathrm{~nm}, \sim 1.44$ vol. \%) were found to offer the most favourable compromise between contrast in CT images and the ability to obtain a homogeneous distribution in 3D space with sufficient particle compactness for local DVC analyses. This property combination was selected following an extensive Micro-focus Computed Tomography $(\mu \mathrm{CT})$-based qualitative assessment on a wide test matrix, that included 38 materials manufactured with a range of possible particle compositions, mean sizes and concentrations. By comparing the tensile behaviour of the particle-adapted material alongside its particlefree counterpart, we demonstrate through the application of in situ Synchrotron Radiation Computed Tomography (SRCT) that the macro- and micromechanical responses of the newly developed CFRP are consistent with standard production materials indicating its suitability as a model system for mechanistic investigations.
\end{abstract}

\section{Introduction}

One of the many strategies for achieving a carbon neutral economy by the 2050s is the use of lightweight, adaptable materials, with high specific properties for transport applications. In this regard, Carbon-Fibre Reinforced Polymers (CFRPs) outperform many monolithic materials, and are increasingly used in 


\section{Journal of Composite Materials (2020)}

DOI: $10.1177 / 0021998320966388$

transport applications due to their desirable strength- and stiffness-to-weight characteristics. However, any material to be certified for use in high performance and safety critical structural applications, must be accompanied by a good understanding of its mechanical behaviour [1]. As such, knowledge of damage initiation and propagation in composites, and the transition from subcritical to critical damage is key to the design process, along with the development of improved materials [2], [3].

CFRPs are known to display complex failure modes, typically involving multiple interacting damage mechanisms, occurring over varying length-scales. For example, fibre breaks are highly localized forms of damage, and are limited to a few micrometers in scale. Delaminations on the other hand may occur over millimetre to metre scales, depending on the structure's size and geometry [4]. In tension, the failure of fibres within $0^{\circ}$ plies is regarded as a critical damage mechanism, with the strength of an axially loaded unidirectional (UD) composite being dominated by fibre strength [4], [5], [6]. Understanding the fibre fracture process, therefore, becomes essential for achieving a comprehensive interpretation of CFRP tensile failure, alongside the various other forms of composite sub-critical damage [7], [8].

A range of predictive models have been developed and adapted to simulate the processes that lead to ultimate failure in fibre fracture-dominated situations [4]. These commonly include the following concepts:

- Fibre strength as a stochastic quantity [9]. This is typically presumed to follow a Weibull distribution [10].

- Stress (or strain) transfer mechanisms, or load shedding rules [11]. Around single fibre breaks, the surrounding matrix transfers load, primarily in shear, into adjacent fibres [9]. This stress transfer mechanism reintroduces stress into the broken fibre [12], while the break (i.e. crack) also triggers local stress concentrations in the nearby intact fibres [13], [14]. The stress (or strain) concentration factors (SCFs), defined as the relative change in the average stress (or strain) over the cross-section of an adjacent fibre due to the presence of a fibre break, increases the probability of fracture in these intact fibres [1], [13], [15], [16].

- Evolution of fibre breaks with ongoing loading. Fibre breaks are initially spatially distributed and evolve into cluster of breaks. These clusters consist of multiple interacting fibre breaks, prior to the onset of unstable failure [1], [4], [5], [17], [18], [19], [20].

- The propagation of a 'critical cluster' in an unstable, self-sustaining manner. This is associated with the catastrophic failure of the composite [9], [13], [18], [20].

Acknowledging that damage in composite materials is a three-dimensional (3D) problem, and in the endeavour to validate these underpinning assumptions of fibre failure-based strength theories, recent years have seen a departure from 'traditional' damage assessment methods (e.g. optical microscopy and material sectioning [21], acoustic emission, [2], [6], [21], scanning electron microscopy [22] etc.) in favour of Xray Computed Tomography $(\mathrm{CT})$; with this non-invasive 3D imaging technique being further divided into Micro-focus Computed Tomography $(\mu \mathrm{CT})$ and Synchrotron Radiation Computed Tomography (SRCT). While both acquisition methods can deliver usable micrometre and sub-micrometre voxel resolution levels, superior scans are commonly achieved through SRCT (the beam is brighter, monochromatic, coherent and parallel, thereby avoiding issues such as beam hardening and cone beam artefacts, and facilitating phase enhanced imaging [23]). Moreover, $\mu \mathrm{CT}$ is characterised by significantly longer scanning times, on the order of hours, as opposed to seconds for SRCT, especially at sub-micrometre resolutions [23]. Near composite failure this may be expected to promote hold-at-load artefacts, whereby the viscoelastic response of the polymer matrix may result in time-dependent strain variation and subsequent failure of UD composites [6], [24], [25], [26]. 


\section{Journal of Composite Materials (2020)}

DOI: $10.1177 / 0021998320966388$

The pairing of SRCT with in situ tensile loading has led to a paradigm shift in identifying detailed sequences of damage accumulation down to fibre-level, in 3D, within the bulk of real engineering materials under load [1], [4], [19], [20], [27], [28]. As such, considerable progress was made in terms of model validation [29] by specifically studying the evolution of breaks with ongoing loading [1], [4], [19], [20]. Recently, developments have seen the use of uninterrupted scan strategies [19] (but at the expense of image quality), mainly aimed at capturing the critical nature of damage required to trigger final failure. Nevertheless, this remains a somewhat hypothetical concept, as even the latest SRCT instruments do not permit observations to be made at sufficiently high temporal resolution to capture the final state of damage in the last instant prior to failure [19].

Experimental studies involving the stress (or strain) transfer mechanisms associated with fibre fracture have received limited attention despite developments in CT methods. Therefore, direct experimental evidence to validate one of the underpinning assumptions of fibre failure-based strength theories remains primarily based on Raman spectroscopy studies [30], [31], [32], [33]. These measurements are, however, limited to the surface of the material (as they require visible light transmission), and have been generally performed on model microcomposites with a sparse distribution of fibres, which may not exhibit fullyrepresentative stress/strain states.

To bridge this gap in the literature the authors have considered the coupling of in situ SRCT with Digital Volume Correlation (DVC) for a strain-based quantification of the local deformation surrounding fibre break sites in representative materials subjected to a continuously applied load [8]. An extension of the twodimensional (2D) Digital Image Correlation (DIC) technique [34], DVC was developed for volumetric measurements, and initially demonstrated as a means to estimate the effective continuum strain tensor in trabecular bone subjected to axial compression [35]. The general objective of the DVC is to track a set of multiple reference volumes between the undeformed and subsequent deformed states of a structure, in order to determine the associated displacement vectors. This may be achieved by employing a correlation criterion (function) to identify underlying patterns within a time (applied load)-series volumetric data set [35], [36]. In combination with high-resolution 3D imaging, DVC is a tool capable of quantifying the internal/bulk microstructural responses of a material between different load states, by extracting relevant parameters (e.g. local displacements and strains) [37].

Ideally, X-ray-based DVC analysis requires the presence of a sufficiently stochastic, isotropic array of features (or texture) which provides X-ray contrast/attenuation [38], [39]. The highly anisotropic and somewhat regular/self-similar microstructures found in conventional unidirectional CFRPs at high fibre volume fractions are, therefore, intrinsically challenging for DVC, particularly for the analysis of displacements/strains along the fibre direction. The simple cylindrical structure and relatively smooth surfaces of the filaments yields little structural variation along the fibre direction, leading to poor image correlation, and correspondingly inaccurate displacement estimates in this direction within a given ply [40].

This paper is the first from a series documenting the application of DVC to displacement and/or strain measurements parallel to the fibre orientation, ultimately aimed at mapping strain fields at fibre break sites [7], [8] and other damage critical sites. Here we focus on the material development required to perform such measurements. Following a similar approach to that taken by Brault et al. [41] to generate individual features unique to a particular sub-set, the authors have explored the insertion of sparse populations of significantly smaller particles $(<1 \mu \mathrm{m}$, as opposed to $150 \mu \mathrm{m}$ used in [41]) within the matrix to act as displacement trackers - i.e. fiducial markers.

Whilst adding particles to a material clearly changes its microstructure, previous studies have shown that for low particle concentrations, the mechanical properties of thermosetting matrices can be largely 


\section{Journal of Composite Materials (2020)}

DOI: $10.1177 / 0021998320966388$

preserved [42], [43]. This work represents the first detailed evaluation of potential fiducials for DVC on CFRP materials at truly micromechanical levels, resulting in the development of a model system, which may have wide utility for understanding fundamental mechanisms of failure and quantitatively informing mathematical model development.

\section{Materials and methods}

\subsection{Material development}

\subsubsection{Carbon-fibre and resin system}

Fibres suitable for drum winding and prepreg production were selected, specifically, a $12 \mathrm{~K}$ non-twisted TORAYCA T700SC-50C tow (Toray Industries Inc., Tokyo, Japan [44]). This is a polyacrylonitrile-based (PAN) high strength (4900 MPa), standard-modulus (230 GPa) fibre, with a $7 \mu \mathrm{m}$ nominal diameter [44]. This fibre type has been extensively used in previous works [1], [4], [5], [19], [28], providing a database of comparable measurements. A SiPreg KTA 313/SR 8500 dual-component epoxy matrix was used (Sicomin, Châteauneuf-les-Martigues, France [45]). As per the manufacturer specifications, the resin is characterized by a low initial viscosity $\left(7.0 \mathrm{~Pa} . \mathrm{s}\right.$ at $\left.20^{\circ} \mathrm{C}\right)$, low reactivity, and upon curing has a $65 \mathrm{MPa}$ and $3.7 \mathrm{GPa}$ tensile strength and tensile modulus, respectively. For this work, the former characteristics are considered desirable, allowing for both particle doping and fibre impregnation, without inducing premature curing during manufacture (Section 2.1.3.).

\subsubsection{Particle systems}

To create microstructural fiducial patterns, the resin was filled with dilute concentrations of a range of commercially available particles of approximately spherical shape (US Research Nanomaterials Inc., Houston, TX, USA [46]). In absorption mode X-ray CT, the imaging contrast arises from the different linear attenuation coefficients of the constituent phases [23], [47], [48]. The attenuation coefficient ' $\mu$ ' (dominated by the photoelectric effect) for a specific point $(\mathrm{X}, \mathrm{Y}, \mathrm{Z})$ within the material, is given by [23]:

$$
\mu(X, Y, Z)=K \rho \frac{Z^{4}}{E^{3}}
$$

Equation 1

where ' $K$ ' is a constant, ' $\rho$ ' is the density, ' $Z$ ' the atomic number and ' $E$ ' is the energy of the beam (incident photons), respectively. Fig. 1 presents the mass attenuation coefficient ' $\mu / \rho$ ' for relevant elemental media and compounds, based on data obtained from the National Institute of Standards and Technology (NIST) [49]. As materials with low atomic number exhibit low X-ray attenuation (e.g. carbon), and, therefore, poor imaging contrast relative to the fibres and epoxy resin, the particle systems were selected such that they are characterized by attenuation coefficients higher than that of the composite constituents. Table 1 presents the different concentrations of particles used, expressed in weight $\%$ of the amount of resin used, while Table 2 shows the different particles sizes investigated. 


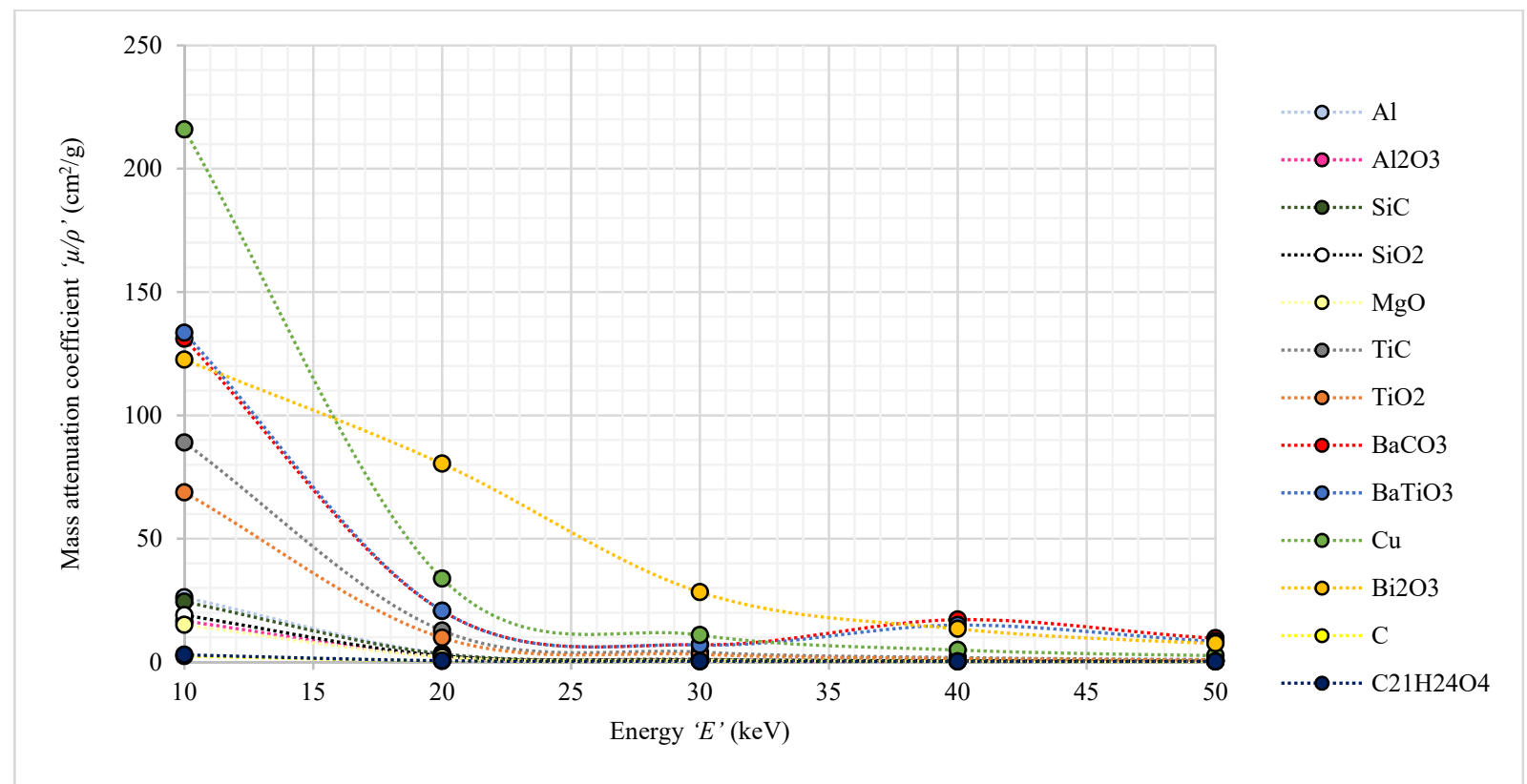

Figure 1 -Attenuation profiles for elemental media and compounds, representative of the different phases: matrix, carbon-fibres and fiducial markers. The attenuation of the matrix was estimated using bisphenol A diglycidyl ether (DGEBA), $\mathrm{C}_{21} \mathrm{H}_{24} \mathrm{O}_{4}$. Based on NIST data [49].

\begin{tabular}{|c|c|c|c|c|c|c|c|c|c|c|}
\hline & \multicolumn{10}{|c|}{ Weight $\%$ in resin $*$} \\
\hline & 0.25 & 0.5 & 1 & 2 & 3 & 4 & 5 & 7.5 & 10 & 15 \\
\hline $\mathrm{Al}$ & $x$ & & $\mathrm{x}$ & & & & $\mathrm{x}$ & & $\mathrm{x}$ & $\mathrm{x}$ \\
\hline $\mathrm{Al}_{2} \mathrm{O}_{3}$ & & & & & & & & $\mathrm{x}$ & $\mathrm{x}$ & \\
\hline $\mathrm{SiC}$ & $\mathrm{x}$ & $\mathrm{x}$ & & & & & & & & $\mathrm{x}$ \\
\hline $\mathrm{SiO}_{2}$ & & & & & & & & $\mathrm{x}$ & $\mathrm{x}$ & \\
\hline $\mathrm{MgO}$ & & & & & & & & $\mathrm{x}$ & $\mathrm{x}$ & \\
\hline $\mathrm{TiC}$ & $\mathrm{x}$ & $\mathrm{x}$ & & & & & & & & \\
\hline $\mathrm{TiO}_{2}$ & & & & & & & $\mathrm{x}$ & $\mathrm{x}$ & $\mathrm{x}$ & \\
\hline $\mathrm{BaCO}_{3}$ & & $\mathrm{x}$ & & & & & & & & \\
\hline $\mathrm{BaTiO}_{3}$ & $\mathrm{x}$ & $\mathrm{x}$ & $\mathrm{x}$ & $\mathrm{x}$ & $\mathrm{x}$ & $\mathrm{x}$ & & $\mathrm{x}$ & & \\
\hline $\mathrm{Cu}$ & $\mathrm{x}$ & $\mathrm{x}$ & $\mathrm{x}$ & & & & & & & \\
\hline $\mathrm{Bi}_{2} \mathrm{O}_{3}$ & & & & & & & & & $\mathrm{x}$ & \\
\hline
\end{tabular}

Table 1 - Experimental matrix showing the particle compositions in conjunction with the concentrations used. *Approximate values based on element (or compound) density. 


\begin{tabular}{|c|c|c|c|c|c|c|}
\hline & \multicolumn{7}{|c|}{ Particle mean size $(\mathrm{nm})^{*}$} \\
\cline { 2 - 7 } & 300 & 400 & 500 & 580 & 600 & 800 \\
\hline $\mathrm{Al}$ & & & & & & $\mathrm{x}$ \\
\hline $\mathrm{Al}_{2} \mathrm{O}_{3}$ & $\mathrm{x}$ & & $\mathrm{x}$ & & & $\mathrm{x}$ \\
\hline $\mathrm{SiC}$ & & & & & $\mathrm{x}$ & \\
\hline $\mathrm{SiO}_{2}$ & & $\mathrm{x}$ & & & & \\
\hline $\mathrm{MgO}$ & $\mathrm{x}$ & & & & $\mathrm{x}$ & \\
\hline $\mathrm{TiC}$ & & & & & & $\mathrm{x}$ \\
\hline $\mathrm{TiO}_{2}$ & $\mathrm{x}$ & & $\mathrm{x}$ & & & \\
\hline $\mathrm{BaCO}_{3}$ & & & & & & $\mathrm{x}$ \\
\hline $\mathrm{BaTiO}_{3}$ & & $\mathrm{x}$ & & & & \\
\hline $\mathrm{Cu}$ & & & & $\mathrm{x}$ & & \\
\hline $\mathrm{Bi}_{2} \mathrm{O}_{3}$ & & & & & & $\mathrm{x}$ \\
\hline
\end{tabular}

Table 2 - Experimental matrix showing the particle compositions in conjunction with the nominal particle sizes used (*as specified by the manufacturer).

\subsubsection{Material manufacturing}

Cross-ply laminates, with a [90/0 $]_{s}$ layup and thickness of $\sim 1 \mathrm{~mm}$ were manufactured by drum winding at KU Leuven, Belgium. Prior to fibre impregnation, the particles were dispersed in the epoxy system using a combination of high-shear mixing and heated ultra-sonication (U100H bath, Ultrawave Ltd., Cardiff, UK [50]). No additional treatment was applied to the particle surfaces. To remove entrapped air, the thermosetting mixture was degassed for 10 minutes at ambient temperature. The amount of resin used was $150 \mathrm{~g}$, with $31.5 \mathrm{~g}$ of hardener, following the manufacturer's specified mixing ratio of 100/21 (by weight). A nominal $25 \%$ tow overlap was targeted during the winding process, with a maximum spool tension of $0.53 \mathrm{~N}$. To control the volume fraction of the matrix following impregnation, the tow was passed through a metering die with an orifice slot of $0.2 \mathrm{~mm} \times 9 \mathrm{~mm}$. The temperature of the tow spreader and final guide roller were set to $50^{\circ} \mathrm{C}$. The fibre sizing was left intact. For a schematic diagram of the manufacturing setup, the reader is referred to [7]. The drum winding process resulted in uniaxial prepreg tape, $\sim 0.25 \mathrm{~mm}$ thick $\mathrm{x} \sim 350 \mathrm{~mm} \mathrm{x} \sim 1900 \mathrm{~mm}$, which was cut and laid up to produce the desired [90/0 $]_{\mathrm{s}}$ cross-ply layup. As indicated in Fig. 2, the prepreg stack was cured in an autoclave for 280 minutes at $0.5 \mathrm{MPa}$ (5 bar) and a maximum temperature of $120^{\circ} \mathrm{C}$. To minimize void content in the cured material, a vacuum of $\sim 0.07 \mathrm{MPa}$ ( $~ 0.7$ bar) was maintained throughout the autoclave process. The particle-modified CFRP is identified as 'doped material' throughout the rest of this paper.

A subsequent set of similar cross-ply laminates was fabricated, without the application of any fiducial markers ('undoped material'). Identical processing parameters (including shear mixing and sonication) were used in the fabrication of both composite types. 


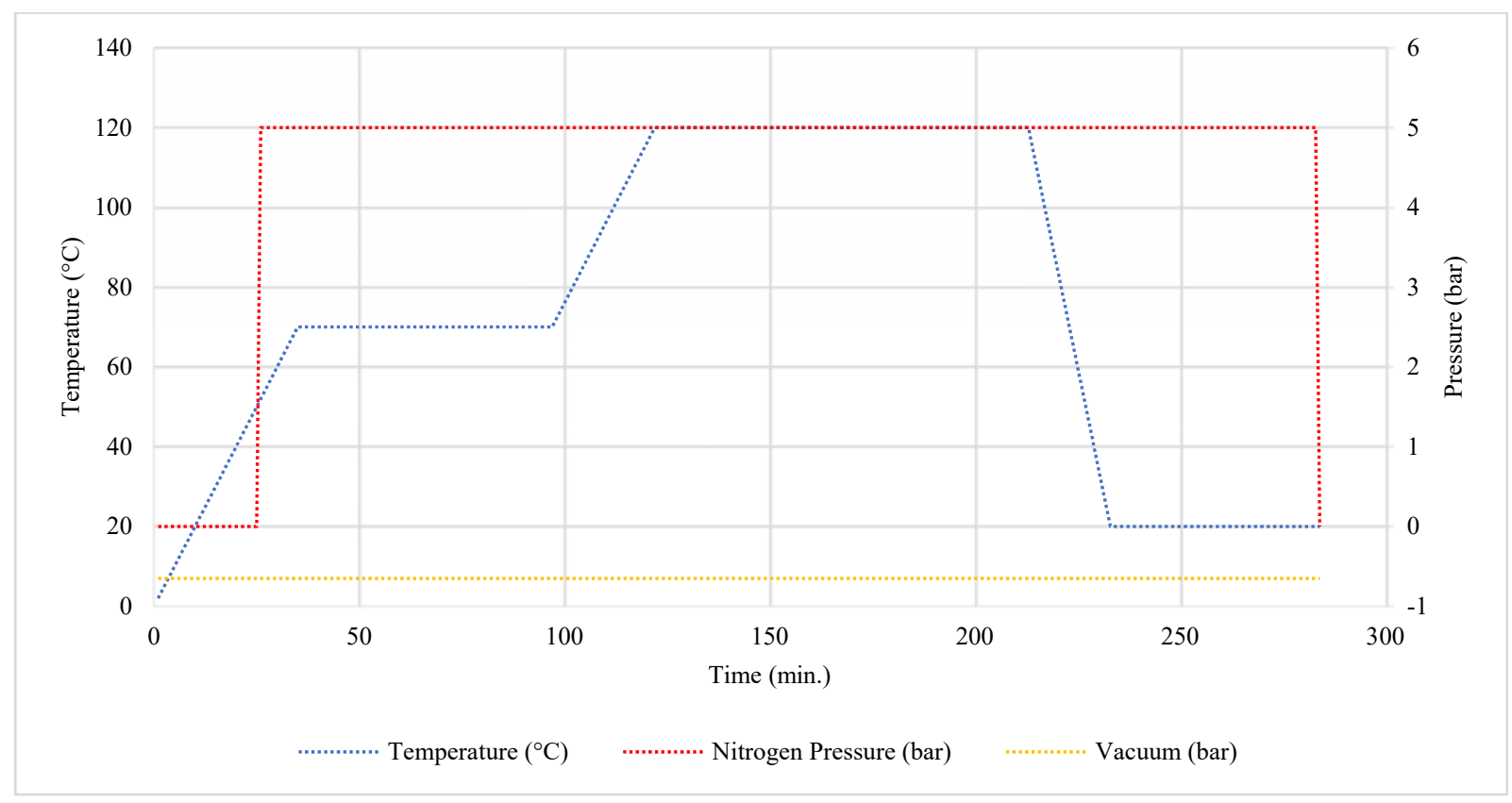

Figure 2 - Schematic illustration of the cure cycle used as part of the autoclave process.

\subsection{Specimen geometry}

\subsubsection{Microstructural analysis}

Unnotched specimens $(\sim 1 \mathrm{~mm} \mathrm{x} \sim 15 \mathrm{~mm} \mathrm{x} \sim 1 \mathrm{~mm})$ were machined via water-jet cutting from the manufactured CFRP plates. Three to six specimens, each representative of a different material, were stacked together to form $75 \mathrm{~mm}$ long 'matchsticks' for conventional static $\mu \mathrm{CT}$ scanning (i.e. no load applied) see Section 2.3.

\subsubsection{Tensile testing}

Double-edge notched specimens were machined via water-jet cutting for in situ SRCT imaging (see Section 2.4.). The geometry is based on previous work of Scott, Schöberl, Garcea, Rosini, Moffat, Wright and co-workers [4], [5], [8], [19], [20], [27], [28], although here the total specimen length was increased to $100 \mathrm{~mm}$, as reported in [8] and [20]. This was performed to (a) minimize the risk of pull-out from the central $0^{\circ}$ portion of the gauge region, and (b) to accommodate a smaller X-ray propagation distance, by providing sufficient clearance between the top of the loading rig and detector optics. Once cut, the T-shaped sections of the specimens were tabbed with $1.5 \mathrm{~mm}$ thick aluminium sheet. Aerospace-grade adhesive, Scotch-Weld EC-9323 B/A (3M Company, Maplewood, MN, USA [51]), was used to bond the tabs onto the CFRP surface. Adhesive curing was performed at $65^{\circ} \mathrm{C}$ for $2 \mathrm{hrs}$ according to the manufacturer's recommendations. The key specimen dimensions, the tabbed assembly and an exemplar microstructure with high contrast fiducial markers are collectively shown in Fig. 3. Tensile loading was performed in situ by using a modified CT5000 single-actuator electromechanical rig (Deben Ltd., Woolpit, Suffolk, UK [52]) retrofitted with a Poly(Methyl Methacrylate) - PMMA reaction tube (25 mm outer diameter and $3 \mathrm{~mm}$ wall thickness). Using position control, loading was performed at a displacement rate of $0.2 \mathrm{~mm} / \mathrm{min}$ up to a prescribed load point. A small applied preload was used (max. $75 \mathrm{~N}$ ) to ensure that the specimen did not 
move during initial acquisition and/or manipulator stage translation. Typically, ten load steps were applied for stepwise in situ measurements, with somewhat smaller load increments being made at high loads, close to failure. This was applied on the basis of the work of Scott et al. [4], where fibre breaks have been shown to accumulate exponentially with applied stress, with the majority of breaks occurring above $~ 90 \%$ UTS. To alleviate potential effects of specimen relaxation under load (and thus potential movement during CT acquisition), scanning was carried out with a slight reduction in load ( 10\%) from the most recent peak level applied.

Based on $\mu \mathrm{CT}$ imaging, three specimens were subjected to SRCT-based tensile testing: one doped with $\mathrm{BaTiO}_{3}$ particles $(400 \mathrm{~nm}, \sim 1.44 \mathrm{vol}$. $\%$, see Section 3.1.) and two undoped: 'A' and 'B'. Table 3 summarizes the double-notched specimens studied, together with the associated fibre volume fractions $\left(V_{f}\right)$, measured through digital segmentation. Due to experimental time constraints, the undoped specimen ' $\mathrm{B}$ ' was not loaded to fracture.

\begin{tabular}{|c|c|c|}
\hline Specimen label & Particle system & $\begin{array}{c}\text { Fibre volume } \\
\text { fraction }\end{array}$ \\
\hline Doped & $\begin{array}{c}\mathrm{BaTiO}_{3}, 400 \mathrm{~nm} \\
\sim 1.44 \text { vol. } \%\end{array}$ & $\sim 55 \%$ \\
\hline Undoped 'A' & \multirow{2}{*}{ N/A } & $\sim 63 \%$ \\
\cline { 1 - 1 } Undoped 'B' & & $\sim 58 \%$ \\
\hline
\end{tabular}

Table 3 - Basic characteristics of the double-notched specimens subjected to SRCT-based tensile testing.
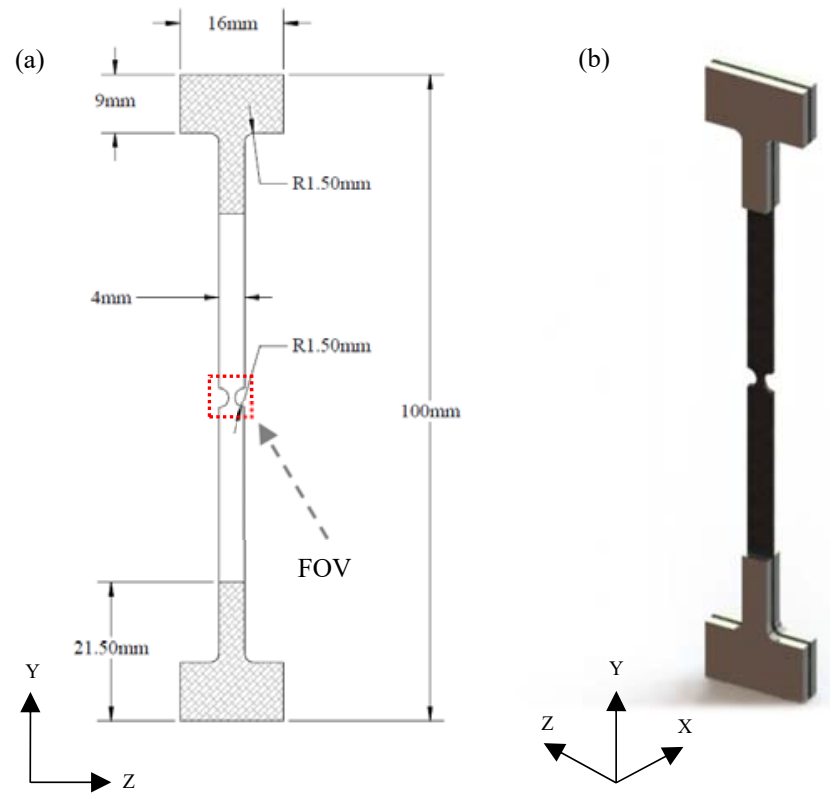

(c)

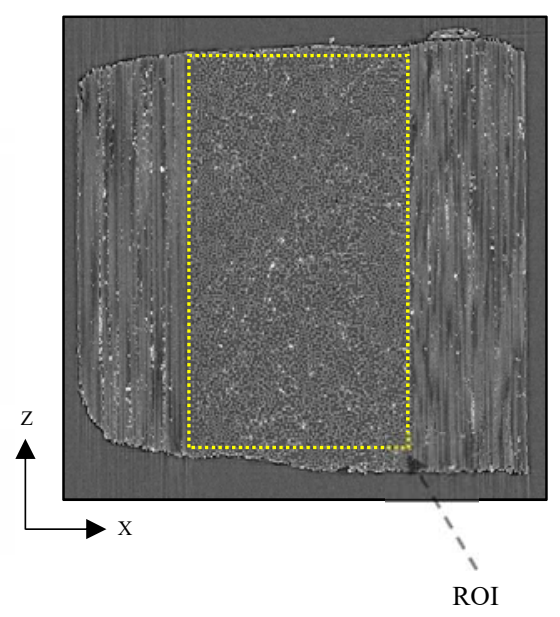

Figure 3 - Tensile specimens: (a) key specimen dimensions and field of view (FOV), (b) tabbed assembly (CFRP plus aluminium tabs), (c) SRCT slice showing a cross-section of the notch region doped with high contrast fiducial markers $\left(\mathrm{BaTiO}_{3}, 400 \mathrm{~nm} \sim 1.44 \mathrm{vol}\right.$.\%), including the region of interest (ROI), which encompasses the $0^{\circ}$ plies. 


\subsection{Micro-focus Computed Tomography}

Micro-focus CT measurements were carried out at the $\mu$-VIS X-Ray Imaging Centre at the University of Southampton, UK. Scans were conducted in a Xradia 510 Versa (Carl Zeiss AG, Oberkochen, Germany [53]) polychromatic system, equipped with a tungsten transmission target. A $2048 \times 2048$-pixel detector was used, with a chip size of $13.5 \mu \mathrm{m}$. To achieve matching SRCT voxel resolution levels, a two-stage magnification approach was implemented (Resolution at a Distance or RaaD [53]), combining the geometric magnification of the X-Ray imaging with a set of barrel-mounted scintillator lenses. Scans were conducted at $20 \mathrm{x}$ magnification, yielding a voxel size ranging from $\sim 0.65 \mu \mathrm{m}$ to $\sim 0.77 \mu \mathrm{m}$. A $2 \mathrm{x}$ detector 'binning' was used, resulting in a maximum field of view (FOV) of $\sim 0.74 \mathrm{~mm} \mathrm{x} \sim 0.75 \mathrm{~mm} \mathrm{x} \sim 0.76 \mathrm{~mm}$. The beam energy was set to $50 \mathrm{kVp}$ and the current to $80 \mu \mathrm{A}$. The number of projections acquired per scan was 1601 , at a maximum exposure of $7 \mathrm{~s}$, resulting in $\sim 3.11 \mathrm{hrs}$ per tomograph. Acquisition was performed over a rotation of $\pm 180^{\circ}$. A source-to-object and object-to-detector distance of $\sim 13 \mathrm{~mm}$ and $\sim 13 \mathrm{~mm}$, respectively, was used. The data was reconstructed using conventional absorption-based Filtered Back Projection (FBP).

\subsection{Synchrotron Radiation Computed Tomography}

In situ SRCT measurements were performed at the ID19 beamline, European Synchrotron Radiation Facility (ESRF), Grenoble, France. A 2560 x 2160-pixel detector was used, with a chip size of $6.5 \mu \mathrm{m}$. Scans, with a monochromatic beam, were conducted at a 10x magnification, yielding a voxel size of 0.650 $\mu \mathrm{m}$ and a FOV of $\sim 1.66 \mathrm{~mm} \mathrm{x} \sim 1.40 \mathrm{~mm} \mathrm{x} \sim 1.66 \mathrm{~mm}$. The beam energy was set to $19 \mathrm{keV}$, with 2996 projections acquired per scan, at an exposure of $25 \mathrm{~ms}$, resulting in $\sim 75 \mathrm{~s}$ per tomograph. Acquisition was performed over a rotation of $180^{\circ}$. A propagation distance of $\sim 30 \mathrm{~mm}$ was used, while the data was reconstructed using conventional absorption-based FBP. Fig. 4 illustrates the SRCT experimental setup.

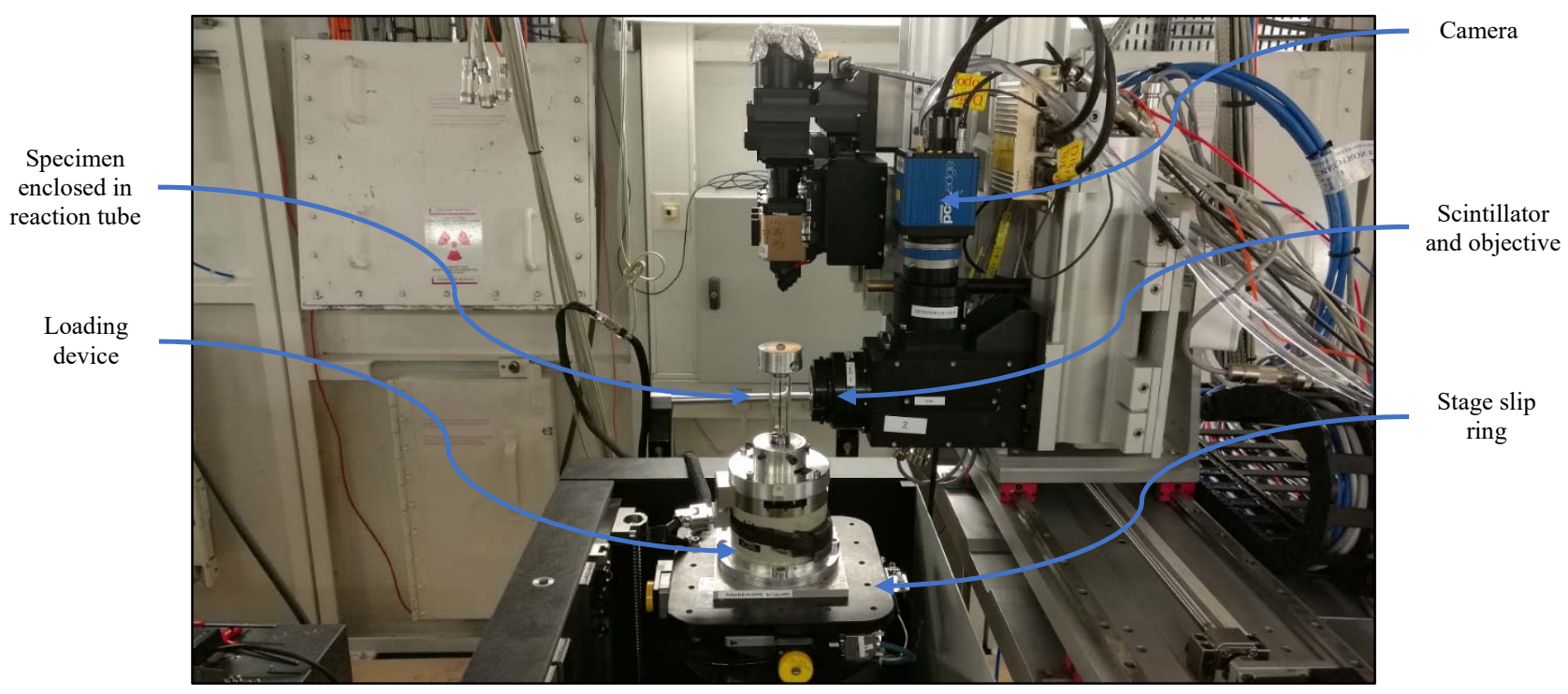

Figure 4-SRCT experimental setup illustrating the key components (ID19 beamline, ESRF). 


\subsection{Image processing}

Volume images were extracted from the centre-notch gauge section of the $0^{\circ}$ plies, ensuring that the same region of interest (ROI) exists across each load step, for each specimen in part (Table 4). Fibre breaks were hand-counted within the volume stack to minimize false positives/negatives. To ensure that no fibre breaks were omitted (and/or mislabelled), three distinct counts (iterations) were performed across each of the volume stacks. The location of each fibre break was marked in Fiji ImageJ [54] with the centroid coordinates being extracted. Attention was given to centre each mark onto the associated fibre break in 3D space, to within a single-voxel. Fibre break centroids were finally sorted into single, non-interacting fibre breaks ('singlets') or clusters of fibre breaks ('N-plets'), whereby $N$ indicates the number of interacting breaks within a given cluster (e.g. three 7-plets are the equivalent of three fibre break clusters, each comprising 7 interacting breaks, and accounting for 21 breaks in total).

Following a similar geometrical (proximity) criterion to that used by Swolfs et al. [1] and Scott et al. [4], a cluster is defined here as two or more broken fibres with an axial and radial separation of 10 and 2 fibre diameters, respectively, measured from centre-to-centre. A fibre diameter of $6.8 \mu \mathrm{m}$ (as opposed to 7 $\mu \mathrm{m})$ was used to set this criterion, as detailed in [55]. This essentially creates a 'bounding cylinder' measuring $136 \mu \mathrm{m}$ in the fibre direction $(2 \times 10 \times 6.8 \mu \mathrm{m})$ and $27.2 \mu \mathrm{m}$ in diameter $(2 \times 2 \times 6.8 \mu \mathrm{m})$ for each fibre break centroid. If more than one fibre break is located within the boundary of this cylinder, then the respective fibre breaks are considered to be part of the same fibre break cluster. It is important to note that the term 'cluster' does not have a consistent definition throughout the literature, so results from different studies must be compared carefully [19]. As noted in Table 4, all post-processing is conducted within a volume of $\sim 0.34 \mathrm{~mm}^{3}$, extracted from the $0^{\circ}$ plies. Additionally, for computational cost reduction reasons, a 32-bit floating point to 8-bit integer conversion was performed for the SRCT data.

\begin{tabular}{|c|c|c|c|c|}
\hline $\begin{array}{c}\text { Slice dimension } \\
\text { (voxels) }\end{array}$ & Doped specimen & $\begin{array}{c}\text { Undoped } \\
\text { specimen 'A' }\end{array}$ & $\begin{array}{c}\text { Undoped } \\
\text { specimen 'B' }\end{array}$ & $\begin{array}{c}\text { ROI volume } \\
\left(\mathrm{mm}^{3}\right)\end{array}$ \\
\hline Coordinate ' $\mathrm{X}$ ' & 650 & 640 & 640 & \multirow{2}{*}{$\sim 0.34$} \\
\hline Coordinate ' $\mathrm{Z}$ ' & 1150 & 1250 & 1250 & \\
\hline Coordinate ' $\mathrm{Y}$ ' & 1670 & 1560 & 1560 & \\
\hline
\end{tabular}

Table 4-ROI from the $0^{\circ}$ plies used for fibre break data quantification (SRCT data, 1 voxel $=0.65 \mu \mathrm{m}$ ).

\section{Results and discussion}

\subsection{Microstructural analysis}

Given the number of materials manufactured, and the evident microstructural variations, initial triage of microstuctures was carried out qualitatively, based on $\mu \mathrm{CT}$ data. This rationale was used to determine the combination of particle composition, size and concentration that results in reasonably homogeneous distributions in 3D space, with sufficient particle compactness for local DVC analyses, without gross anomalies (large voids, clumping etc.). Representative $\mu \mathrm{CT}$ slices from each material are provided in Appendix A. To preserve the tensile behaviour of a commercially representative material, whilst still allowing the application of DVC parallel to the fibre direction [7], [8], [40], the authors have established a series of considerations: 
- Particles must be reasonably attenuating (more so than the carbon-filaments), without introducing X-ray imaging artefacts (particularly streak patterns).

- Particle size must be small enough to allow for incorporation between individual fibres, essentially creating parallel 'strips' of fiducial marks with respect to the fibre direction (Y), minimising influence on fibre packing (and hence misalignment and presence of resin-rich regions).

- Particles should be sufficiently large to be detectable at the available voxel resolution levels (on the order of three voxels across).

- Particle concentration must be low enough to prevent agglomeration, yet sufficient for DVC analyses at microstructural length-scales (on the order of one fibre diameter).

Following the above considerations, the materials doped with various particle system are ranked in Table 5. For more detailed comments, the reader may consult Appendix B. A 'three-tick' system was used to summarize the overall attributes (one tick $=$ poor, two ticks $=$ adequate, three ticks $=$ excellent). 


\begin{tabular}{|c|c|c|c|c|c|}
\hline $\begin{array}{l}\text { Fiducial } \\
\text { marker } \\
\text { system }\end{array}$ & $\begin{array}{l}\text { Overall } \\
\text { ranking }\end{array}$ & $\begin{array}{l}\text { Imaging } \\
\text { contrast }\end{array}$ & $\begin{array}{c}\text { Spatial } \\
\text { distribution }\end{array}$ & $\begin{array}{c}\text { Lack of } \\
\text { agglomerates }\end{array}$ & Key comment \\
\hline $\mathrm{Al}$ & $\checkmark \checkmark \checkmark$ & $\checkmark \checkmark$ & $\checkmark \checkmark \checkmark$ & $\checkmark \checkmark \checkmark$ & $\begin{array}{l}\text { At a concentration of } 10 \mathrm{wt} . \% \text {, aluminium } \\
\text { appears to satisfy the imaging requirements for } \\
\text { local DVC analyses. }\end{array}$ \\
\hline $\mathrm{Al}_{2} \mathrm{O}_{3}$ & $\checkmark$ & $\checkmark$ & $\checkmark \checkmark$ & $\checkmark \checkmark$ & $\begin{array}{l}\text { The } 300 \mathrm{~nm} \text { aluminium oxide system appears } \\
\text { to yield a slightly superior particle deposition } \\
\text { between the individual carbon-filaments, } \\
\text { compared to the } 500 \mathrm{~nm} \text { and } 800 \mathrm{~nm} \\
\text { counterparts, respectively. }\end{array}$ \\
\hline $\mathrm{SiC}$ & $\checkmark$ & $\checkmark \checkmark$ & $\checkmark$ & $\checkmark$ & $\begin{array}{l}\text { The doping with silicon carbide at a } \\
\text { concentration of } 15 \text { wt. \% results in a } \\
\text { microstructure abundant with gross } \\
\text { microstructural anomalies. This fails to satisfy } \\
\text { the established considerations. }\end{array}$ \\
\hline $\mathrm{SiO}_{2}$ & $\checkmark \checkmark$ & $\checkmark$ & $\checkmark \checkmark$ & $\checkmark \checkmark \checkmark$ & $\begin{array}{l}\text { Silicon dioxide }(7.5 \mathrm{wt} . \% \text { and } 10 \mathrm{wt} . \%) \text { with } \\
\text { a particle size of } 400 \mathrm{~nm} \text { performs similar to the } \\
500 \mathrm{~nm} \text { aluminium oxide and } 500 \mathrm{~nm} \text { titanium } \\
\text { oxide systems, respectively, at similar } \\
\text { concentrations. }\end{array}$ \\
\hline $\mathrm{MgO}$ & $\checkmark$ & $\checkmark$ & $\checkmark$ & $\checkmark$ & $\begin{array}{l}\text { The microstructure doped with magnesium } \\
\text { oxide is characterized by an abundance of } \\
\text { agglomerates, particularly at the higher } \\
\text { concentrations. These have a 'crystal-like' } \\
\text { appearance and are differentiated by sharp } \\
\text { edges from the other compositions examined. }\end{array}$ \\
\hline $\mathrm{TiC}$ & $\checkmark$ & $\checkmark \checkmark \checkmark$ & $\checkmark$ & $\checkmark \checkmark$ & $\begin{array}{l}\text { At a size of } 800 \mathrm{~nm} \text {, titanium carbide particles } \\
\text { are identifiable at a concentration of } 0.25 \mathrm{wt} . \% \\
\text { and } 0.5 \mathrm{wt} \% \% \text {, respectively. The imaging } \\
\text { requirements for local DVC analyses are, } \\
\text { however, not satisfied given the sparse spatial } \\
\text { distribution associated with these low } \\
\text { concentration levels. }\end{array}$ \\
\hline $\mathrm{TiO}_{2}$ & $\checkmark \checkmark$ & $\checkmark \checkmark \checkmark$ & $\checkmark \checkmark$ & $\checkmark$ & $\begin{array}{l}\text { Compared to the magnesium oxide counterpart, } \\
\text { titanium oxide agglomerates are no longer } \\
\text { characterized by sharp edges and the overall } \\
\text { abundance is slightly reduced within the } \\
\text { microstructure, notwithstanding that the } \\
\text { particle distribution does not match that of } \\
\text { barium titanate, particularly in terms of inter- } \\
\text { fibre deposition. }\end{array}$ \\
\hline $\mathrm{BaCO}_{3}$ & $\checkmark$ & $\checkmark \checkmark \checkmark$ & $\checkmark$ & $\checkmark \checkmark$ & $\begin{array}{l}\text { The doping with barium carbonate yields } \\
\text { similar results to those obtained by the } \\
\text { titanium carbide system. }\end{array}$ \\
\hline $\mathrm{BaTiO}_{3}$ & $\checkmark \checkmark \checkmark$ & $\checkmark \checkmark \checkmark$ & $\checkmark \checkmark \checkmark$ & $\checkmark \checkmark \checkmark$ & $\begin{array}{l}\text { The particle distribution remains homogenous } \\
\text { throughout the concentrations investigated, } \\
\text { with the desirable particle compactness for } \\
\text { local DVC analyses achieved at the highest } \\
\text { concentration of } 7.5 \mathrm{wt} \% \text {. Also, the barium } \\
\text { titanate system does not appear to be prone to } \\
\text { agglomerate formation. }\end{array}$ \\
\hline $\mathrm{Cu}$ & $\checkmark$ & $\checkmark \checkmark \checkmark$ & $\checkmark \checkmark$ & $\checkmark \checkmark$ & $\begin{array}{l}\text { The copper system is overly attenuating (see } \\
\text { Fig. 1), such that at the energies available, it } \\
\text { promoted imaging artefacts, visible as streak } \\
\text { patterns surrounding the fiducial markers. }\end{array}$ \\
\hline $\mathrm{Bi}_{2} \mathrm{O}_{3}$ & $\checkmark$ & $\checkmark \checkmark \checkmark$ & $\checkmark$ & $\checkmark$ & $\begin{array}{l}\text { Like copper, bismuth oxide is too attenuating } \\
\text { compared to carbon at the beam energies } \\
\text { available in the present work. }\end{array}$ \\
\hline
\end{tabular}

Table 5 - Ranking system highlighting the overall attributes of the different materials manufactured. 


\section{Journal of Composite Materials (2020)}

Based on this qualitative analysis, two fiducial markers systems appear to outperform the others on balance: (1) barium titanate (400 nm, 7.5 wt. \%) and aluminium (800 nm, 10 wt. \%) - Fig. 5. This can be further reduced to the barium titanate system based on the following considerations:

- A better inter-fibre deposition is achieved, which may be attributed to a smaller particle size.

- Higher intrinsic density, which translates into a lower volumetric content of $\sim 1.44$ vol. $\% v s$. $\sim 4.17$ vol. \% (considered favourable for preserving the mechanical behaviour of standard production materials).

- More attenuating at the energies available, which results in a superior imaging contrast next to the carbon-filaments.

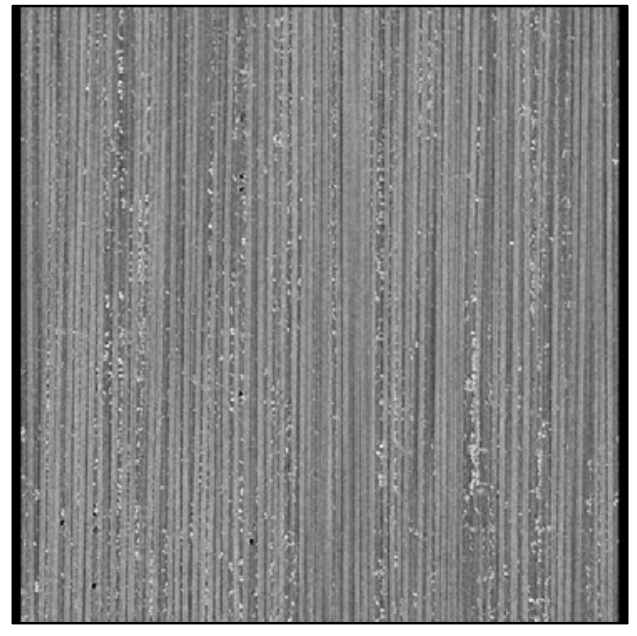

Al 800 nm, 10 wt. \% (slice 423)

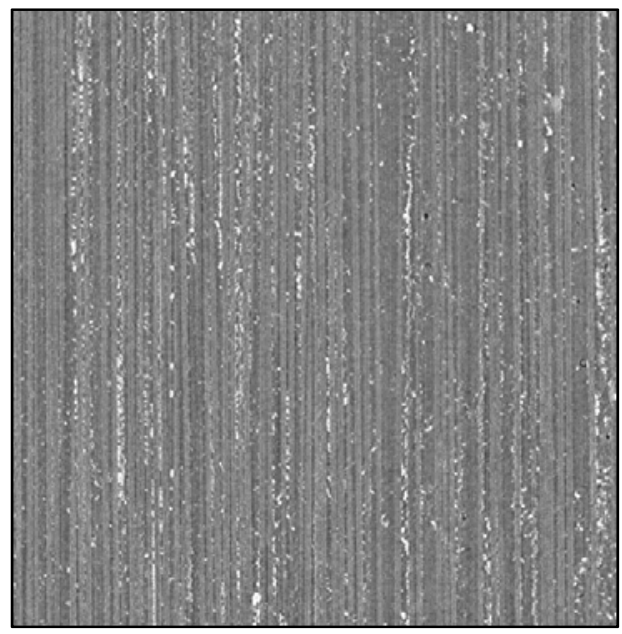

$\mathrm{BaTiO}_{3} 400$ nm, 7.5 wt. \% (slice 457)

Figure 5 - Representative $\mu C T$ slices showing the doping of the CFRP with aluminium and barium titanate, respectively $\left(0^{\circ}\right.$ plies shown).

As such, the barium titanate particles ( $400 \mathrm{~nm}, \sim 1.44$ vol. \%) were judged to offer the most favourable compromise between contrast in CT images and the ability to obtain a homogeneous distribution in 3D space with a sufficiently fine particle distribution for local DVC analyses. Using a threshold of 48/255 for a fully stretched greyscale, the average microvoid content for this material was computed at $\sim 0.1 \mathrm{vol} . \%$, with a corresponding standard deviation of $\sim 0.04 \%$ across the stack (i.e. individual CT slices). The result is consistent with the acceptable levels of less than 1 vol. \% in aerospace-grade applications [56]. The low levels of microvoid content are primarily attributed to the autoclave curing, rather than being an intrinsic characteristic of the drum winding manufacturing process. This becomes more obvious if the CT slices shown here are compared to those in [57], whereby the lack of autoclave curing in a similar filament wound material resulted in fewer voids, but with a substantially larger size: $15 \mu \mathrm{m}$ in diameter and $105 \mu \mathrm{m}$ in length, where the length of the void was aligned with the fibre axis.

\subsection{Fibre break behaviour}

A summary of fibre break behaviour as a function of loading is shown in Table 6. Load is presented as a function of force applied, stress (minimum nominal cross-section of the $0^{\circ}$ plies, as in [1], [4], [19]) and fraction of specimen UTS, respectively. It is clear that the undoped specimens achieve significantly higher 


\section{Journal of Composite Materials (2020) \\ DOI: $10.1177 / 0021998320966388$}

peak nominal stress (in excess of $\sim 3000 \mathrm{MPa}$ ) $c f$. the doped composite ( 2300 MPa). Of the undoped samples, only specimen 'A' was taken to final fracture, failing at $3651 \mathrm{MPa}$. The different failure stresses can be expected to be somewhat governed by difference in the volume fraction of fibres $(\sim 55 \% v s . \sim 63$ $\%$ ), rather than just the presence of the fiducial marker system. It is noted that:

- It is not the doped specimen that manifests an anomalous behaviour, but rather the undoped specimen ' $A$ '. More specifically, the failure stress of the composite is surprisingly high for the fibre type used, even if the higher volume fraction is accounted for - on the order of $15 \%$ above an equivalent fibre strength of $4900 \mathrm{MPa}$.

- The double-edge notched specimens used are expected to experience high specimen-tospecimen variability due to the small gauge volumes. This is because any intrinsic flaws (or the lack of) in the fibres will have a higher impact on such a small gauge volume. In this context, according to the weakest link theory (i.e. Weibull distribution), very small volumes are found to exhibit high strengths [1]. For example, Tanaka et al. [58] have shown that the average size of critical flaws decreased with decreasing gauge length, whereby a higher fibre strength was reported in conjunction with smaller flaw sizes. Likewise, an experimental size-scaling is reported by Okabe and Takeda [59]. Therefore, it seems possible that the undoped specimen 'A' may have been simply a region which was characterized by fewer flaws within the load bearing section of $\sim 1 \mathrm{~mm}^{3}$.

- As noted in the introduction, the mechanical properties of the thermosetting matrices can be preserved, provided that the particle concentration used is low; and since the matrix is responsible for the load transfer around a fibre break, it may also be expected that the micromechanical response of the composite is not fundamentally interfered with.

Fig. 6 shows that fibre breaks accumulate exponentially with applied stress in all three specimens, as reported in [1], [4], [5] and [19]. The two undoped specimens ' $A$ ' and ' $B$ ' show reasonable consistency in terms of accumulation rate, with a slightly more rapid accumulation in the latter. Conversely, the doped specimen exhibits the most rapid accumulation of breaks, particularly noticeable above a composite stress of $\sim 2000 \mathrm{MPa}$. This trend holds if the volume fraction differences are accounted for in terms of equivalent fibre stresses for the two materials, in spite of the subsequent shift that results over the horizontal axis position of the undoped specimen curves are swapped, with undoped specimen ' $A$ ' exhibiting a slightly earlier (lower stress) onset of fibre breaks, $c f$. undoped specimen 'B'.

Fig. 7 exemplifies the same effect in terms of fraction of specimen UTS. Likewise, it indicates that the total number of breaks close to fracture is on the same order for doped and undoped materials ( 913 and 873 breaks, respectively), resulting in a difference of less than $\sim 5 \%$ - notwithstanding the slightly different fraction of UTS achieved in each case ( $98 \%$ and $95 \%$, respectively). Given the lower fibre volume fraction of the doped specimen it can be noted that the proportion of fibres fractured is actually higher in the doped case. However, the statistical nature of fibre behaviour should be recognised, that otherwise identical specimens, representative of T700-series composite, have been reported to exhibit greater variability than seen between the current doped and undoped materials. This is particularly reported in [19], whereby specimens were characterised by 581 and 418 breaks, respectively, at $99.9 \%$ UTS within the load bearing reduced cross-section of $0.45 \mathrm{~mm}^{2}$ - implying that one material presented $\sim 40 \%$ variation in number of breaks. In this context, the presence of $\mathrm{BaTiO}_{3}$ particles does not appear to have had an exceptional effect on the total number of breaks at fracture, and from this perspective, the doped material replicates the essential behaviours of the undoped counterpart, allowing it to be considered as a useful model system. 


\section{Journal of Composite Materials (2020)}

\section{DOI: $10.1177 / 0021998320966388$}

We note that the accumulation rates may be influenced by the volume fraction of fibres. A high fibre volume fraction material has more intact fibres closely-packed around any given broken one, which may be anticipated to result in a stronger 'shielding effect' [13]. On this basis, numerical models indicate that for a random packing, the nearest (intact) neighbouring fibres shield the second nearest neighbouring fibres from the stress concentration associated with a fibre break. Indeed, a higher fibre volume fraction results, on average, in more intact fibres at small distances from the break, and thus with high SCFs. However, when the SCFs are compared at a fixed radial distance from a broken fibre, the higher fibre volume fraction results in a lower SCF [13]. In turn, this 'shielding effect' may translate into an overall accumulation of breaks, with the shallower trend seen in the undoped specimen ' $A$ '.

The total number of fibre breaks found in the present work is consistently higher than that previously reported in the literature, based on an aerospace-grade CFRP with similar reinforcing fibres (i.e. T700series) [1], [4], [19]. For example, Swolfs et al. [1] reported less than 500 breaks $/ \mathrm{mm}^{3}$ at $94 \%$ specimen UTS, which is reasonably consistent with that reported by Scott et al. [4] and Garcea et al. [19], respectively. While it is beyond the scope of this work to establish why this is the case, the higher number of fibre breaks reported here may be associated with intrinsic defects arising from the prepreg drum winding process (e.g. abrasion of the fibre surfaces by the metering die, guide rollers etc.) and/or during the lay-up stage, which was not automated, and thus involved extensive manual intervention. The fact that a CFRP based on T700-series fibres and manufactured via filament winding can exhibit a considerably higher number of breaks, as opposed to its aerospace-grade counterpart, is also shown by Scott [60] and Morton [61], acknowledging that the filament wound materials in [60] and [61] were not subjected to autoclave curing. It is also worth noting that given the combination of individual microvoids and a low void volume fraction, no obvious/direct mechanistic correlation was found between the location of the broken fibres and the location of microvoids, nor between the total number of breaks and the volume fraction of microvoids. This is in contrast to that reported in [57], whereby significantly larger, and more numerous voids (by vol.), than found in the present work, were shown to have a clear influence on fibre break location. In [57], a significant proportion of fibre breaks occurred within half a fibre diameter of a void. 
Journal of Composite Materials (2020)

DOI: 10.1177/0021998320966388

\begin{tabular}{|c|c|c|c|c|c|c|c|}
\hline \multirow{5}{*}{ (a) - Doped specimen } & Load $(\mathrm{N})$ & 600 & 750 & 800 & 850 & 900 & 950 \\
\hline & Stress in $0^{\circ}$ plies $(\mathrm{MPa})$ & 1432 & 1790 & 1909 & 2029 & 2148 & 2267 \\
\hline & Specimen UTS (fraction) & 0.62 & 0.77 & 0.82 & 0.88 & 0.93 & 0.98 \\
\hline & $\begin{array}{l}\text { Number of } \\
\text { total breaks }\end{array}$ & 1 & 14 & 47 & 108 & 357 & 913 \\
\hline & $\%$ of total breaks & 0.11 & 1.53 & 5.15 & 11.83 & 39.10 & 100 \\
\hline Failure load $(\mathrm{N})$ & 970 & & & & & & \\
\hline $\begin{array}{l}\text { Failure stress in } 0^{\circ} \text { plies } \\
(\mathrm{MPa})\end{array}$ & 2315 & & & & & & \\
\hline $\begin{array}{l}\text { Minimum cross-sectional } \\
\text { area of } 0^{\circ} \text { plies }\left(\mathrm{mm}^{2}\right)\end{array}$ & 0.419 & & & & & & \\
\hline
\end{tabular}

\begin{tabular}{|c|c|c|c|c|c|c|c|}
\hline \multirow{5}{*}{ (b) - Undoped specimen } & Load $(\mathrm{N})$ & 900 & 1200 & 1250 & 1300 & 1350 & 1450 \\
\hline & Stress in $0^{\circ}$ plies $(\mathrm{MPa})$ & 2163 & 2885 & 3005 & 3125 & 3245 & 3486 \\
\hline & Specimen UTS (fraction) & 0.59 & 0.79 & 0.82 & 0.86 & 0.89 & 0.95 \\
\hline & $\begin{array}{l}\text { Number of } \\
\text { total breaks }\end{array}$ & 20 & 283 & 385 & 490 & 612 & 873 \\
\hline & $\%$ of total breaks & 2.29 & 32.42 & 44.10 & 56.13 & 70.10 & 100 \\
\hline Failure load $(\mathrm{N})$ & 1519 & & & & & & \\
\hline $\begin{array}{l}\text { Failure stress in } 0^{\circ} \text { plies } \\
(\mathrm{MPa})\end{array}$ & 3651 & & & & & & \\
\hline $\begin{array}{l}\text { Minimum cross-sectional } \\
\text { area of } 0^{\circ} \text { plies }\left(\mathrm{mm}^{2}\right)\end{array}$ & 0.416 & & & & & & \\
\hline
\end{tabular}

\begin{tabular}{|c|c|c|c|c|c|}
\hline \multirow{5}{*}{ (c) - Undoped specimen } & Load (N) & 900 & 1050 & 1200 & 1350 \\
\hline & Stress in $0^{\circ}$ plies $(\mathrm{MPa})$ & 2055 & 2397 & 2740 & 3082 \\
\hline & Specimen UTS (fraction) & \multicolumn{4}{|c|}{ N/A } \\
\hline & $\begin{array}{l}\text { Number of } \\
\text { total breaks }\end{array}$ & 25 & 102 & 266 & 661 \\
\hline & $\%$ of total breaks & 3.78 & 15.43 & 40.24 & 100 \\
\hline Failure load $(\mathrm{N})$ & N/A & & & & \\
\hline $\begin{array}{l}\text { Failure stress in } 0^{\circ} \text { plies } \\
(\mathrm{MPa})\end{array}$ & N/A & & & & \\
\hline $\begin{array}{l}\text { Minimum cross-sectional } \\
\text { area of } 0^{\circ} \text { plies }\left(\mathrm{mm}^{2}\right)\end{array}$ & 0.438 & & & & \\
\hline
\end{tabular}

Table 6-Summary of fibre break behaviour as a function of applied load, stress and \% UTS: (a) doped specimen, (b) undoped specimen 'A', (c) undoped specimen 'B'. Based on in situ SRCT tensile data. 


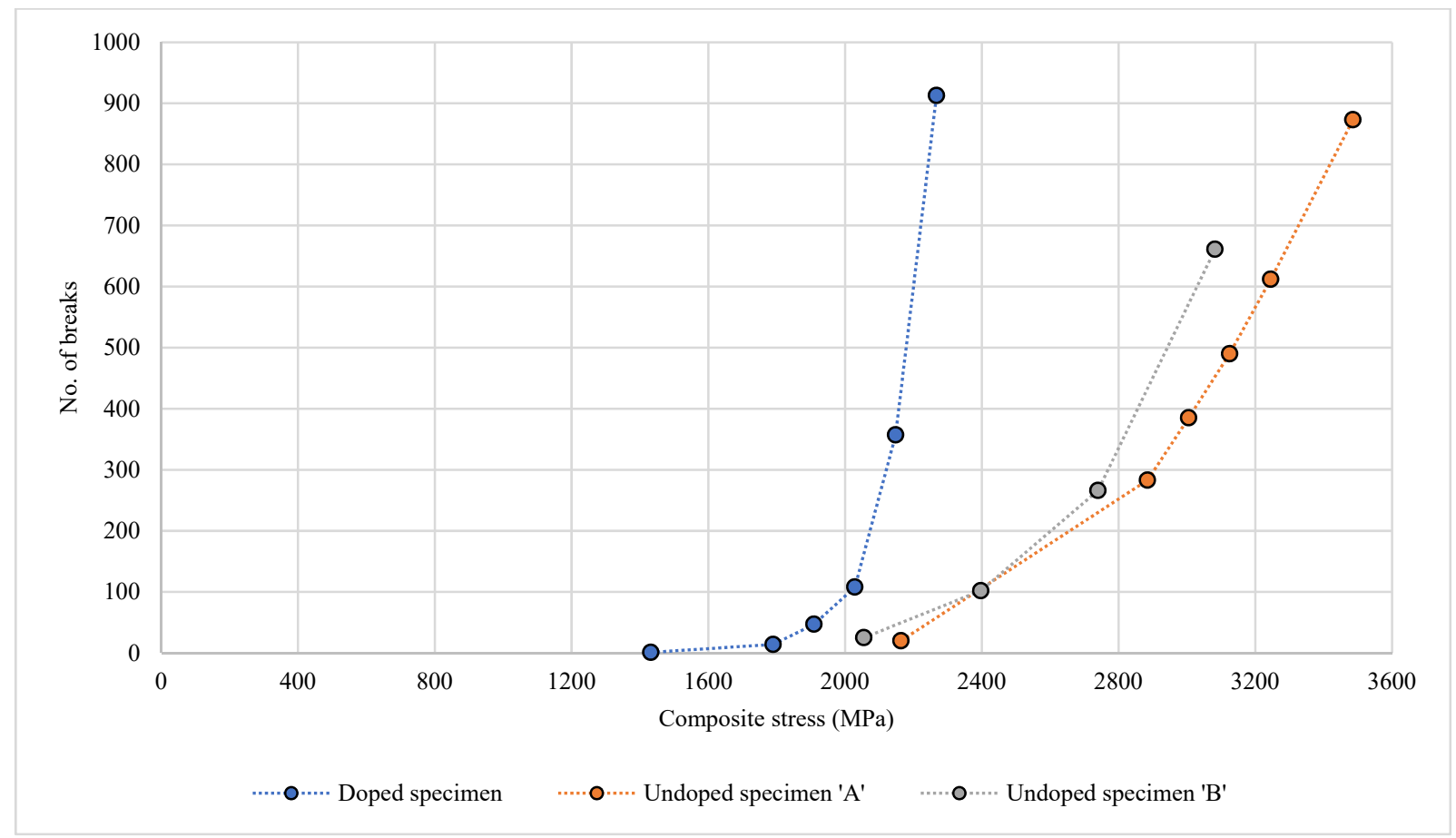

Figure 6 -Fibre break accumulation as a function of applied stress for the three specimens subjected to in situ SRCT tensile testing. Data shown for an equivalent ROI volume of $\sim 0.34 \mathrm{~mm}^{3}$ for each specimen.

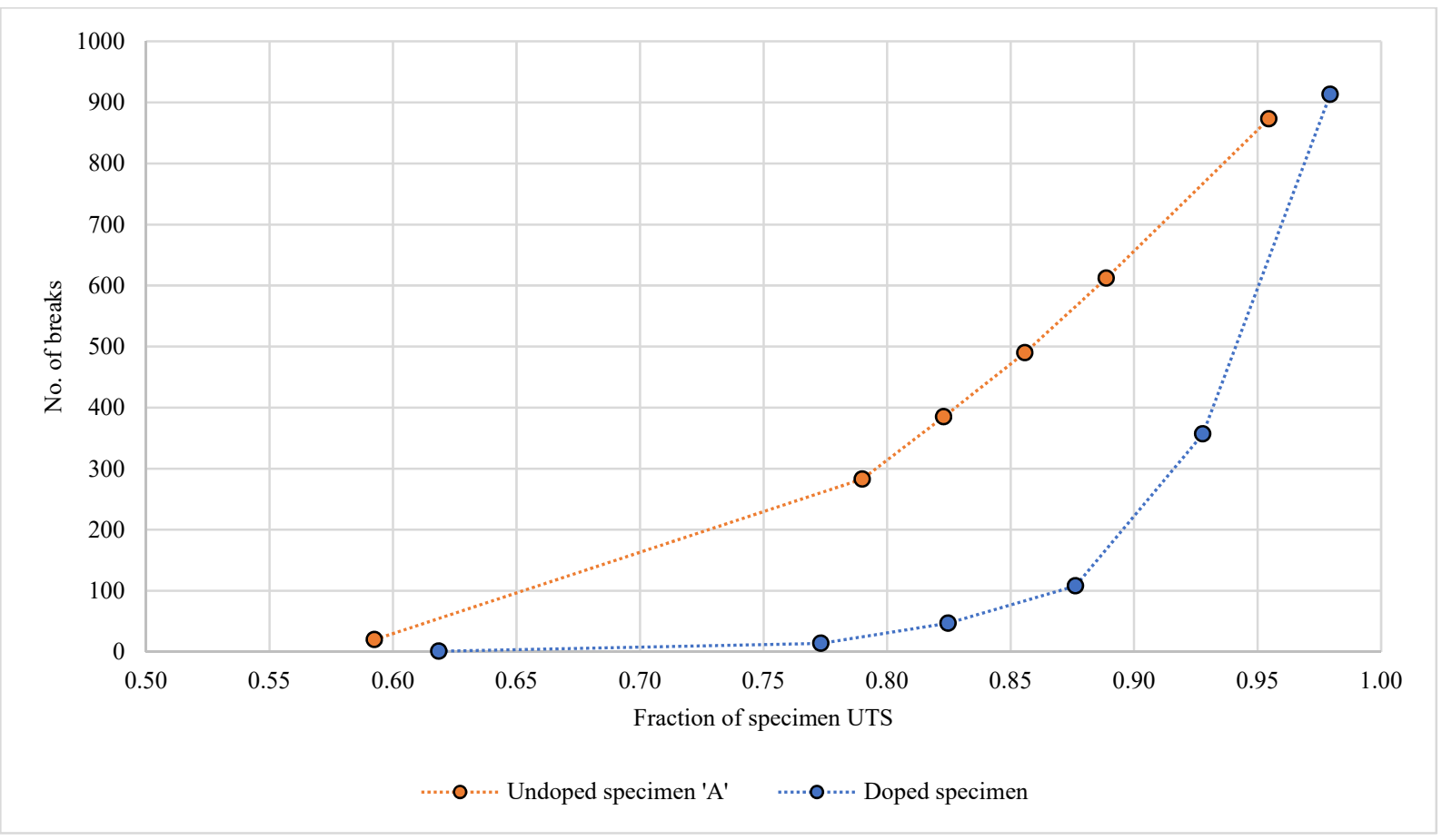

Figure 7 - Fibre break accumulation as a function of \% UTS for the two specimens loaded to fracture. Based on in situ SRCT data. Data shown for an equivalent ROI volume of $\sim 0.34 \mathrm{~mm}^{3}$ for each specimen. 


\section{Journal of Composite Materials (2020)}

\section{DOI: 10.1177/0021998320966388}

The specimen variability becomes even more evident if the fibre break behaviour is decoupled into singlets (Fig. 8) and fraction of singlets to N-plets (Fig. 9), respectively. It can be observed that the rate of singlet accumulation in the undoped specimen ' $\mathrm{B}$ ' matches more to that in the doped specimen, as opposed to that in the undoped specimen 'A'.

The doped specimen is also associated with the lowest number of singlets (421), which is ultimately linked to the lowest fraction of singlets to N-plets (46\%). As the difference in the number of singlets between the specimens is considerably higher compared to that reported in the literature (e.g. 339 vs. 331 at $99.9 \%$ UTS in [19]), it would initially appear that doping with barium titanate has had an effect on the distribution of non-interacting fibre breaks. However, also shown in [19] is that even larger differences can be expected in terms of the proportion of singlets to N-plets ( $c f$. total number of breaks), for identical specimens: $58 \%$ and $79 \%$, respectively - a difference which is undoubtedly higher than found here between the doped and undoped specimen 'A'.

Furthermore, while Fig. 9 shows a general decrease in the proportion of singlets to N-plets, the trend is only monotonic in the case of the undoped specimen ' $\mathrm{A}$ '. This occurs due to the appearance of clusters of breaks at relatively low applied stresses, that unlike singlets, do not exhibit a particularly steep evolution until closer to failure (i.e. above $~ 90 \%$ UTS) - e.g. the largest cluster (12-plet) in the undoped specimen 'B', appears at an intermediate applied stress of $2397 \mathrm{MPa}$ - forming an 'early cluster'. Taken together, these observations indicate that there is variability in damage progression irrespective of the inclusion of $\mathrm{BaTiO}_{3}$ particles, which is consistent with the specimen-to-specimen variability in fibre break evolution observed in other material systems [19], [61].

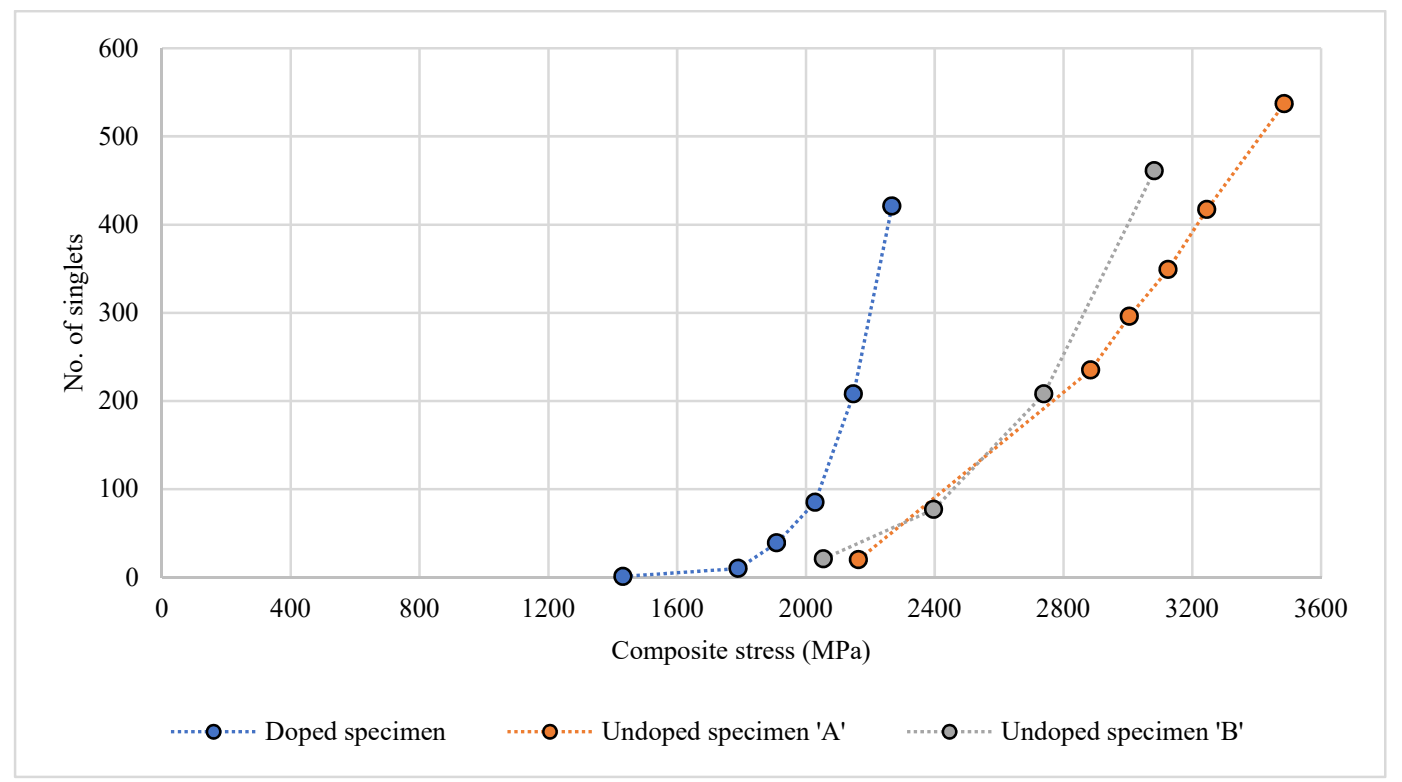

Figure 8-Number of singlets as a function of applied stress for the three specimens subjected to in situ SRCT tensile testing. Data shown for an equivalent ROI volume of $\sim 0.34 \mathrm{~mm}^{3}$ for each specimen. 


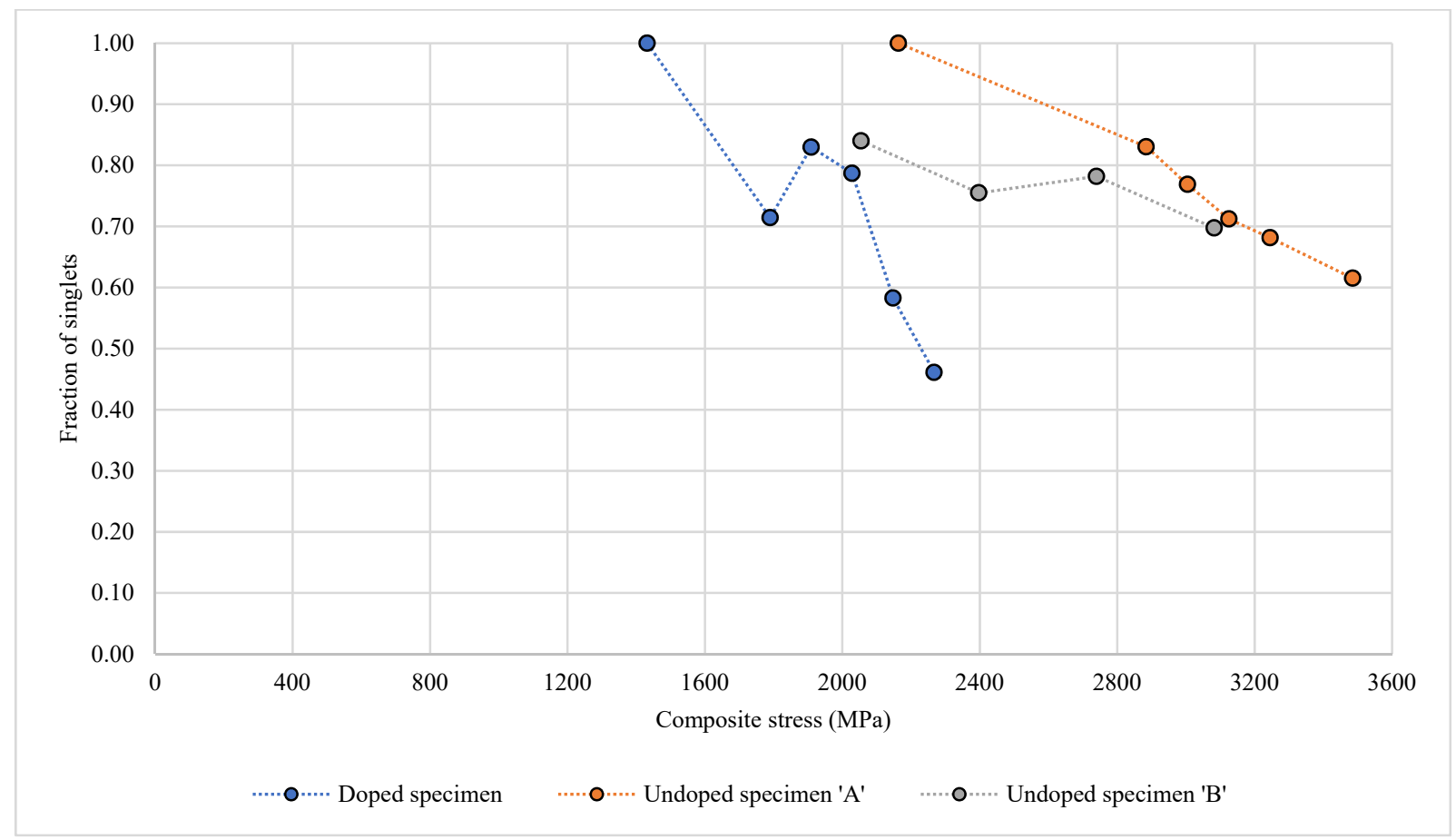

Figure 9 -Fraction of singlets to N-plets as a function of applied stress for the three specimens subjected to in situ SRCT tensile testing. Data shown for an equivalent ROI volume of $\sim 0.34 \mathrm{~mm}^{3}$ for each specimen. Nomenclature example: three 7-plets are counted as 21 breaks in total).

\subsection{Cluster behaviour}

The accumulation of clusters of breaks as a function of applied stress is summarized in Fig. 10, while Fig. 11 presents the visual distribution of these clusters in 3D, at the maximum stress recorded prior to fracture.

The largest clusters found in this work were: a 19-plet in the doped specimen, two 9-plets in the undoped specimen 'A' and an 'early' 12-plet in the undoped specimen 'B'. It was also noted that the largest cluster(s) of one 19-plet in the doped specimen encompasses a similar number of breaks to the two 9-plets in the undoped specimen 'A' (19 vs. 18); with the two 9-plets forming adjacent to each other (Fig. 11).

The 19-plet found in the doped specimen is larger than the 14-plet at $94 \%$ UTS reported in [4], as well as than the 10-plet and 4-plet, respectively, at 99.9\% UTS reported in [19] - notwithstanding that in [19] a cluster of breaks only encompassed breaks that were directly adjacent to one another, potentially making an equivalent 'distance-based' cluster significantly larger (see Section 2.5.). At $93 \%$ UTS, which is closer to the maximum value reported in [4], the largest cluster of breaks in the doped material is a 7-plet, making it half the size of the largest cluster reported in [4]. In terms of the morphology of largest clusters, this is consistent between the doped and undoped materials. It is important to note, that these are all diffuse clusters (Fig. 11), meaning that unlike the largest cluster reported in [4], they are separated by greater axial and radial distances.

Fig. 10 shows a similar trend to that reported in [1], [4], [5] and [19], whereby larger clusters typically appear with increasing stress. Overall, the undoped specimen ' $A$ ' exhibits the shallowest rate of cluster accumulation, followed by the undoped specimen ' $\mathrm{B}$ ' and doped specimen, respectively. As such, there is distinct variability in behaviour, consistent with that reported in [19]. Fig. 10 also shows that for both 
material types, large clusters of breaks generally form without a reduction in the number of smaller clusters. Furthermore, a 'break-by-break' accumulation with applied stress is not observed for the larger clusters. A notable example is the 'early' 12-plet in the undoped specimen 'B', which formed in a single increment or 'burst', and does not exhibit any further growth. This behaviour generally agrees with the experimental data previously reported in [1] and [4] for hold-at-load scans. Again, the doped material is seen to replicate the key behaviour (cluster formation) of undoped, and more broadly, other carbon-fibre composite systems, validating its use as a model system, with the capability to allow tracking of local strains [7].

Ultimately, within the statistical power of the current sample gauge volumes, it appears that the behaviour of clusters is stochastic, whereby specimen failure is likely to be determined by intrinsic stochastic factors, such as fibre strength and local microstructure [19], rather than particularly the inclusion of barium titanate. A much larger number of specimens would need to be examined to provide a statistically significant conclusion regarding the relative contribution of the fiducial markers compared to the intrinsic variability. This, however, is not trivial to achieve in practice due to the limited availability and cost of the SRCT beam time required to achieve such results.

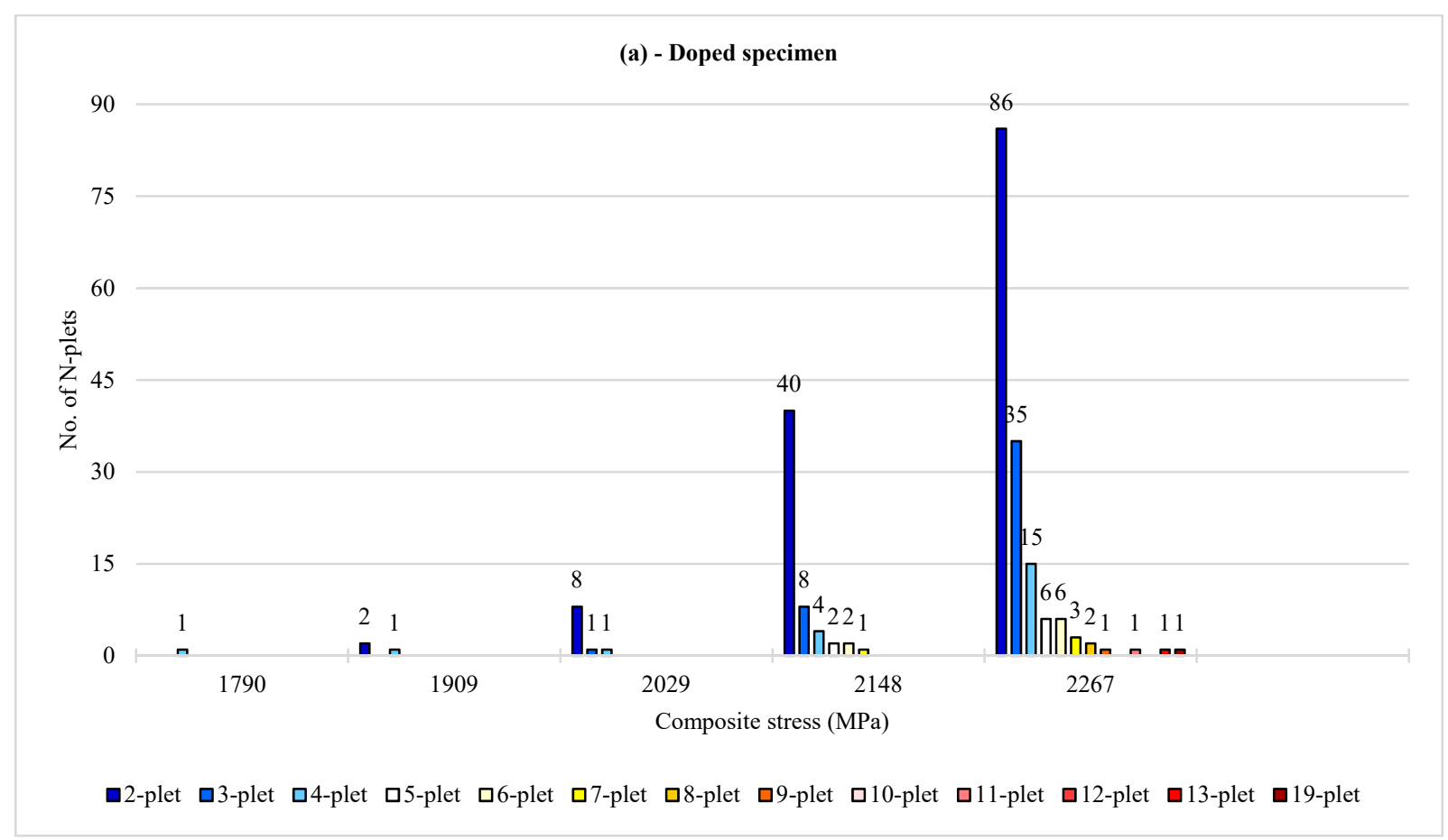



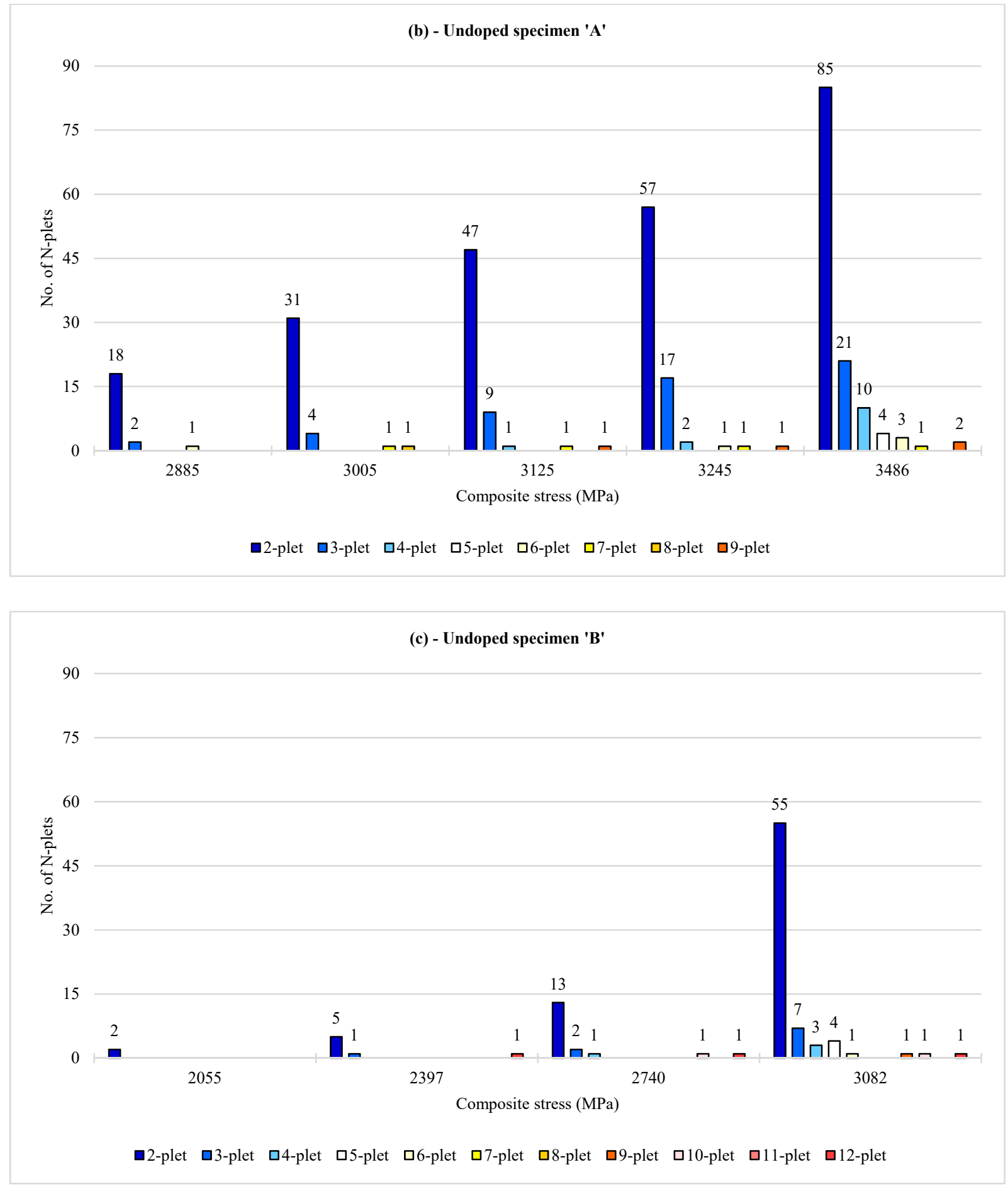

Figure 10 - Distribution of N-plets as a function of applied stress for the three specimens subjected to in situ SRCT tensile testing: (a) doped specimen, (b) undoped specimen ' $A$ ', (c) undoped specimen ' $B$ '. Data shown for an equivalent $R O I$ volume of $\sim 0.34 \mathrm{~mm}^{3}$ for each specimen. 
1021

(a) Doped specimen

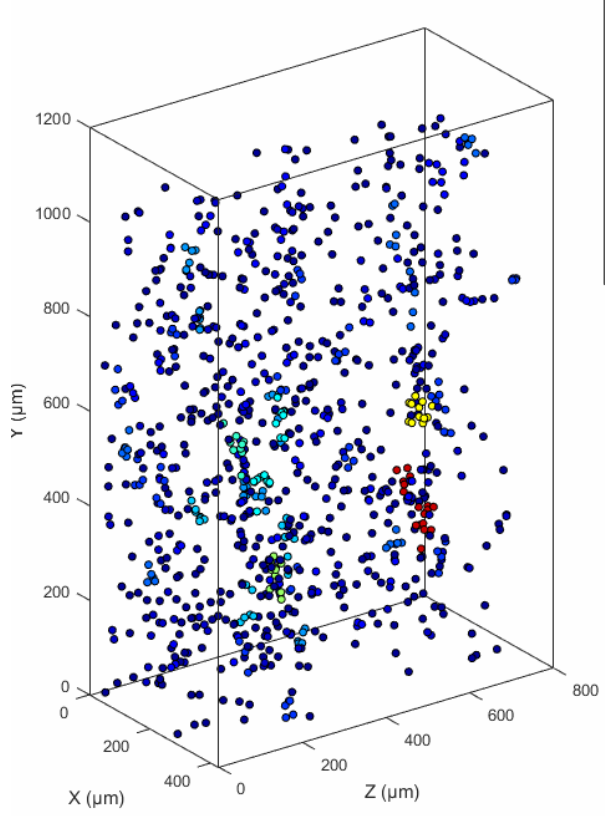

(b) Undoped specimen 'A'

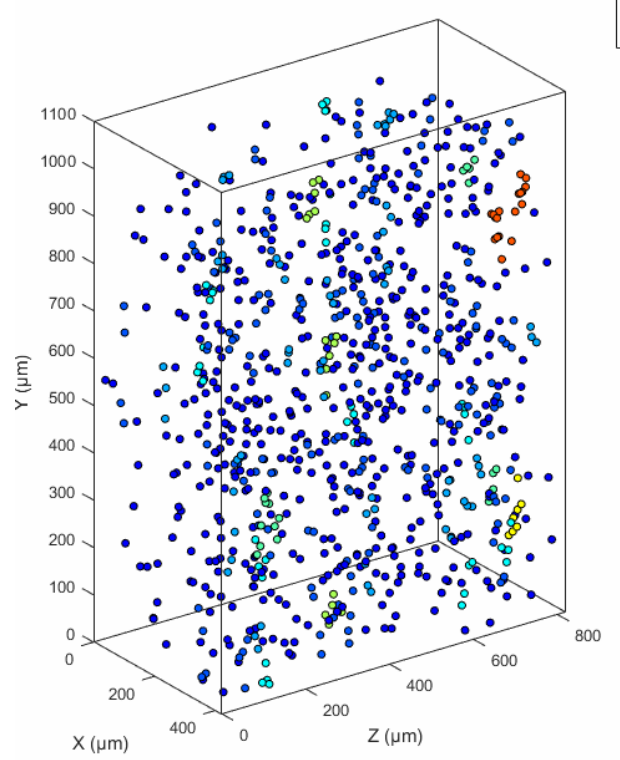

(c) Undoped specimen 'B'

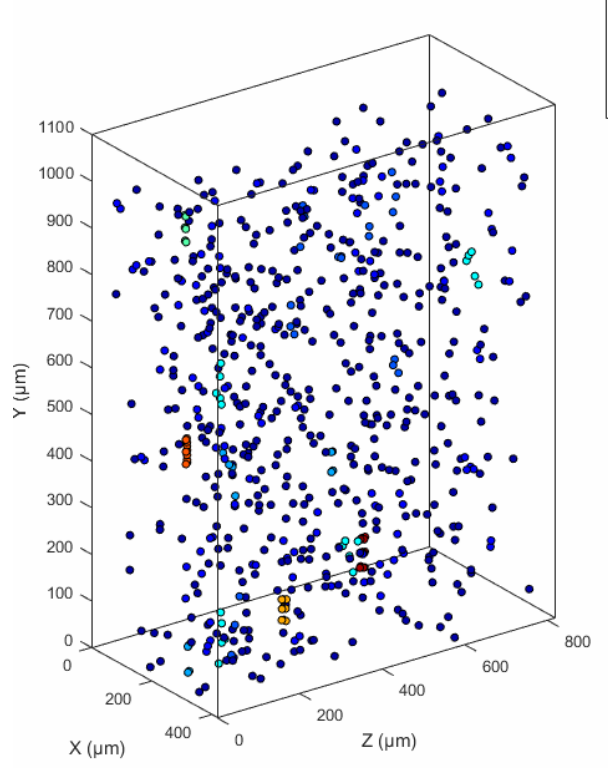

Figure 11 - Distribution of $N$-plets in 3D space at the maximum stress recorded prior to fracture: (a) doped specimen - $2267 \mathrm{MPa}$, (b) undoped specimen 'A'-3486 MPa, (c) undoped specimen 'B' - $3082 \mathrm{MPa}$. Visualizations reconstructed from break centroid coordinates. Each volume corresponds to $\sim 0.34 \mathrm{~mm}^{3}$. 


\section{Summary and conclusions}

A model Carbon-Fibre Reinforced Polymer composite was developed to permit the application of Digital Volume Correlation to displacement and/or strain measurements parallel to the fibre orientation, with the ultimate goal of allowing the mapping of strain fields at fibre break sites. To generate individual features unique to a particular sub-set, the work has explored the insertion of sparse populations of submicrometre particles within the matrix to act as fiducial markers.

To preserve the tensile behaviour of a commercially representative material, whilst still allowing the application of DVC parallel to the fibre direction, a series of considerations were established. The key tradeoff required ensuring that the volume fraction of fiducial markers was able to satisfy the imaging requirements, yet was low enough to minimize any substantial disruption in the separation and packing of fibres at tow-level. Out of the 38 test materials manufactured, barium titanate particles ( $400 \mathrm{~nm}, \sim 1.44$ vol. $\%$ ) were found to offer the most favourable compromise between contrast in CT images and the ability to obtain a homogeneous distribution in 3D space with sufficient particle compactness for local DVC analyses. This property combination was selected following an extensive $\mu \mathrm{CT}$-based qualitative assessment on a range of possible particle compositions, mean sizes and concentrations.

In situ SRCT and subsequent image analysis has shown that the response of the doped material is mechanistically representative of undoped materials made by the same manufacturing route, and is consistent with other materials made by other processes - at least in terms of the fibre fracture response. Some variability in mechanical behaviour is discerned between individual specimens, and material types (doped and undoped), which may be attributable to both manufacturing inconsistency and a potential contribution of the doping particles. Notwithstanding these effects, we identify the doped materials as a suitable model to characterise for the first time the localised, three-dimensional load shedding processes associated with fibre break accumulation within the bulk of CFRPs.

While the development of the present material is mainly intended to promote the understanding of the fundamental aspects of UD composite tensile failure, a similar methodology may be applied to off-axis ply orientations. Furthermore, acknowledging that the benefits of displacement/strain mapping should outweigh differences in the material behaviour, we envisage the methodology being adapted to probe the understanding of composite behaviour not only under different loading conditions (e.g. compression, torsion, time-varying), but also at larger length-scales (e.g. up to the structural level) and in the context of multiaxial or discontinuous reinforcements. 


\section{Acknowledgements}

The research leading to these results has been conducted within the framework of the FiBreMoD project and has received funding from: (1) the European Union's Horizon 2020 research and innovation programme under the Marie Skłodowska-Curie grant agreement No. 722626, and (2) the $\mu$-VIS X-Ray Imaging Centre at the University of Southampton, supported by EPSRC grant agreement No. EP/H01506X/1.

The authors would like to acknowledge the European Synchrotron Radiation Facility (ESRF) for provision of synchrotron radiation facilities and would like to thank Dr. Lukas Helfen and Ms. Elodie Boller for assistance in using beamline ID19. Accompanying acknowledgement is given to Dr. Richard Boardman, Dr. Kathryn Rankin, Dr. Orestis Katsamenis and Mr. Nicholas Hale from the $\mu$-VIS X-Ray Imaging Centre at the University of Southampton. Mr. Stephen Wilby from the Engineering Materials Group at the University of Southampton is also credited with assistance during the experimental campaign. Credit is further extended to Mr. Simon Beever - University of Southampton Engineering Design and Manufacturing Centre (EDMC) and Mr. Adrian Walker - Safire Associates UK for the short notice water-jet cutting of various components required for the experimental work. 
Journal of Composite Materials (2020)

DOI: $10.1177 / 0021998320966388$

\section{Appendix A - Micro-focus Computed Tomography}

Representative $\mu \mathrm{CT}$ slices from each of the CFRPs fabricated. FOV of $\sim 730 \mu \mathrm{m} \times \sim 730 \mu \mathrm{m}$ per slice.

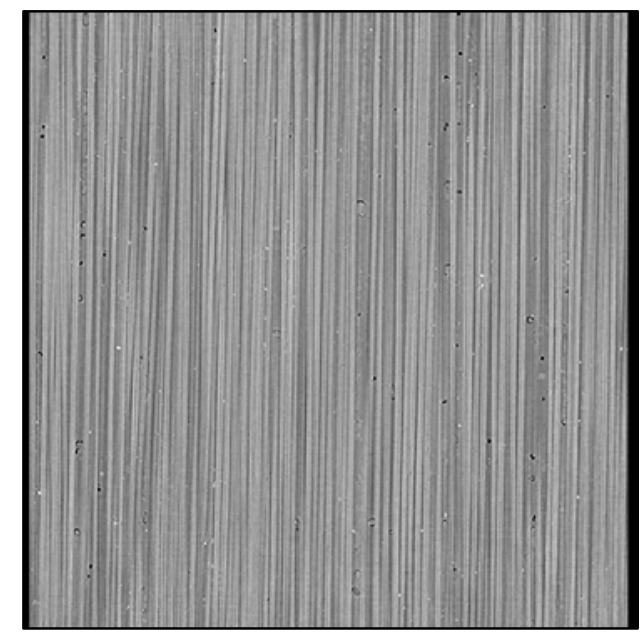

Al 800 nm, 0.25 wt. \% (slice 426)

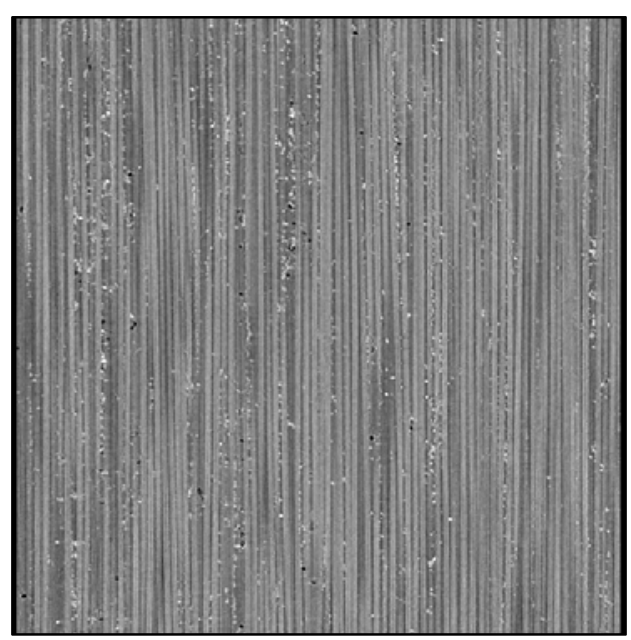

Al 800 nm, 5 wt. \% (slice 541)

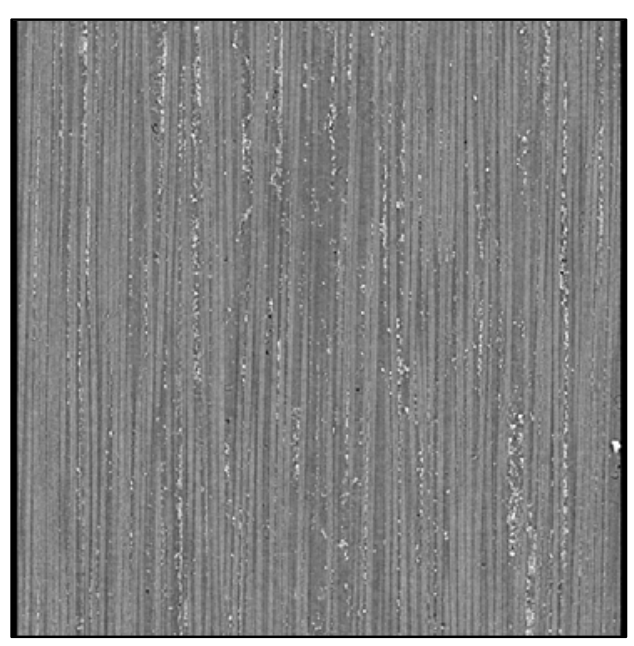

$\mathrm{Al}_{2} \mathrm{O}_{3} 300$ nm, 7.5 wt. \% (slice 435)

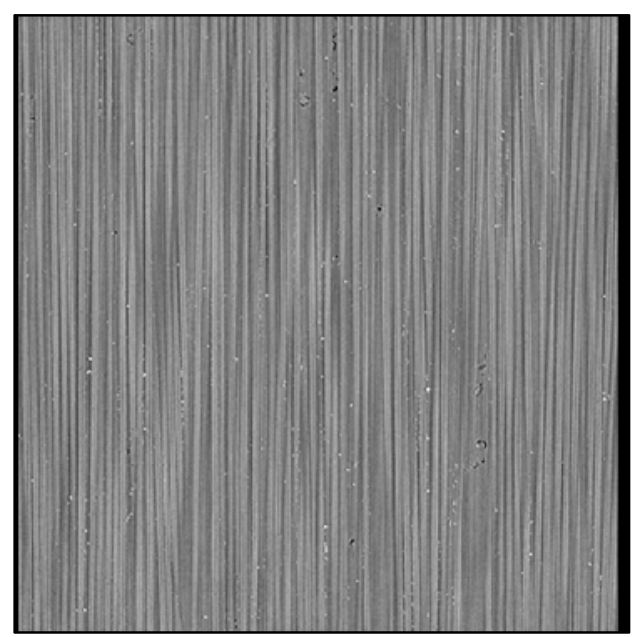

Al 800 nm, 1 wt. \% (slice 542)

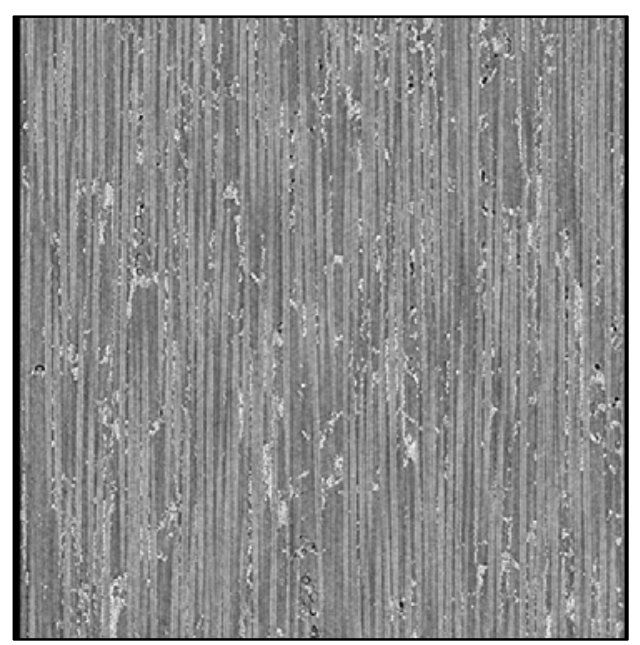

Al 800 nm, 15 wt. \% (slice 583)

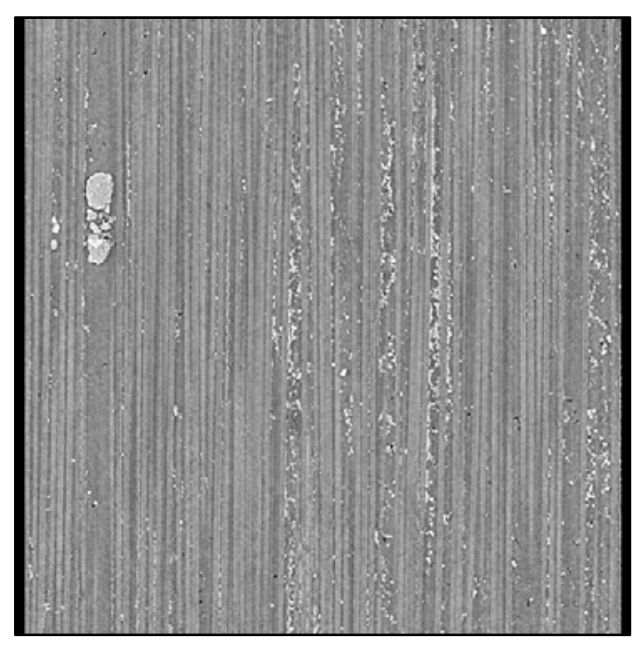

$\mathrm{Al}_{2} \mathrm{O}_{3} 300 \mathrm{~nm}, 10$ wt. \% (slice 402) 
Journal of Composite Materials (2020)

DOI: $10.1177 / 0021998320966388$

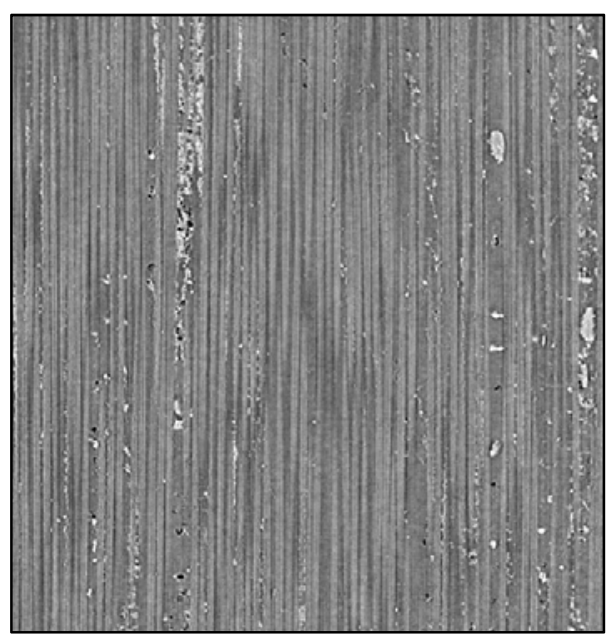

$\mathrm{Al}_{2} \mathrm{O}_{3} 500$ nm, 7.5 wt. \% (slice 386 )

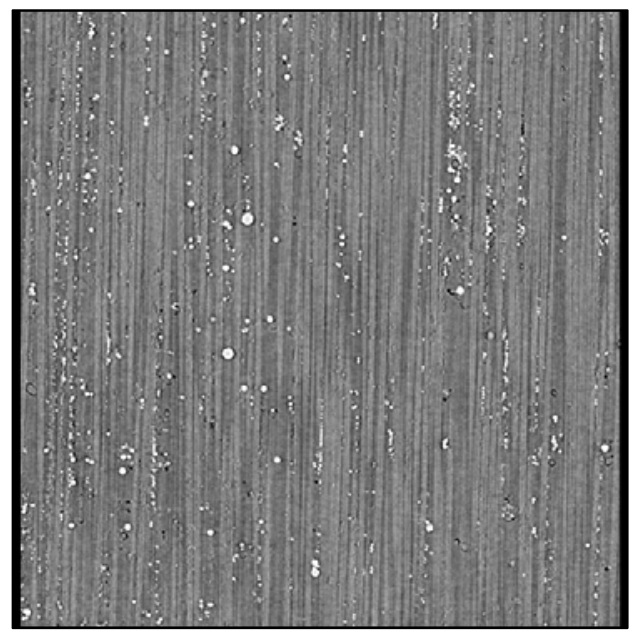

$\mathrm{Al}_{2} \mathrm{O}_{3} 800$ nm, 7.5 wt. \% (slice 420)

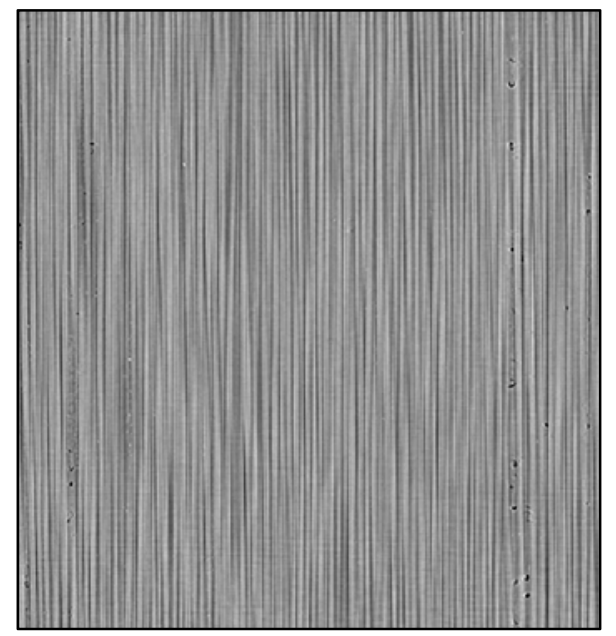

SiC 600 nm, 0.25 wt. \% (slice 644)

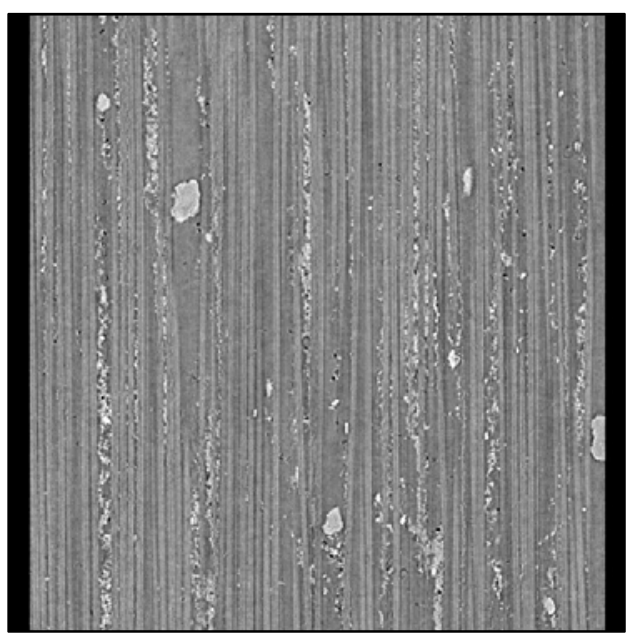

$\mathrm{Al}_{2} \mathrm{O}_{3} 500$ nm, 10 wt. \% (slice 341)

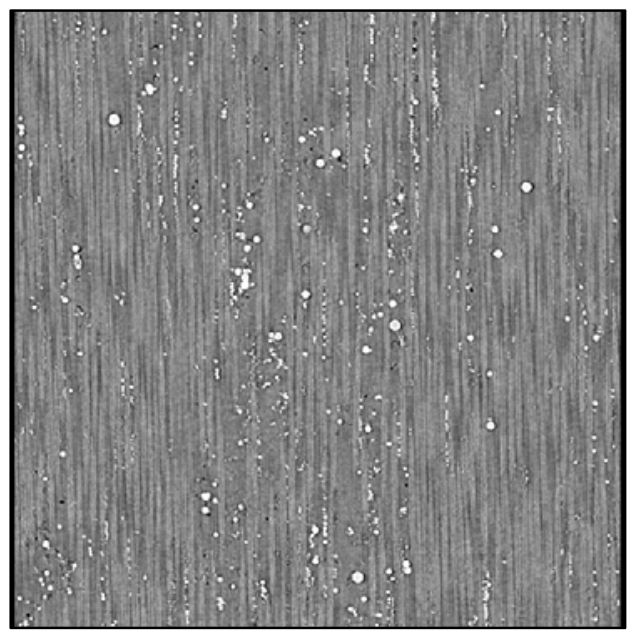

$\mathrm{Al}_{2} \mathrm{O}_{3} 800$ nm, 10 wt. \% (slice 546)

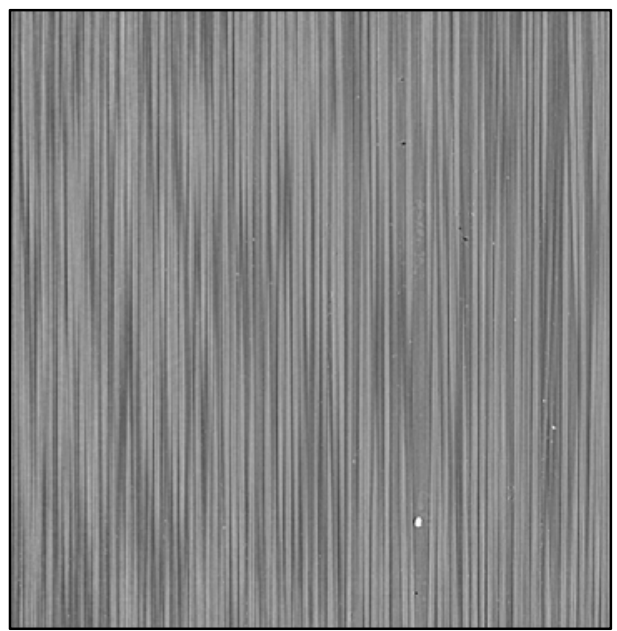

SiC 600 nm, 0.5 wt. \% (slice 552) 
Journal of Composite Materials (2020)

DOI: $10.1177 / 0021998320966388$

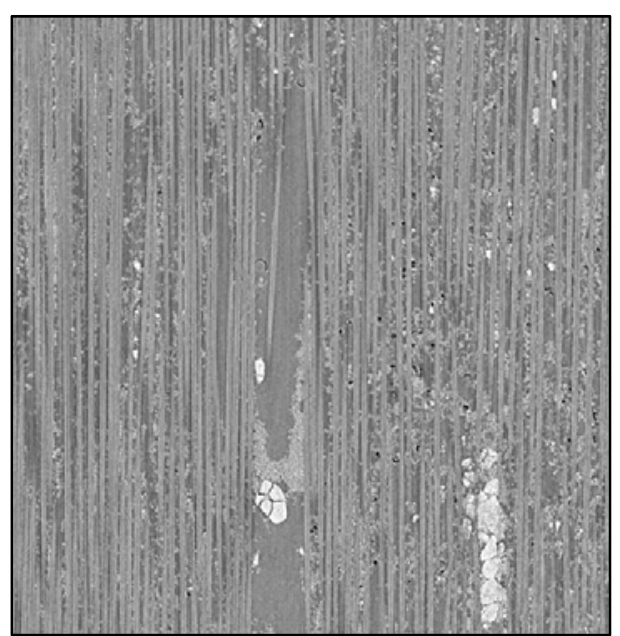

SiC 600 nm, 15 wt. \% (slice 425 )

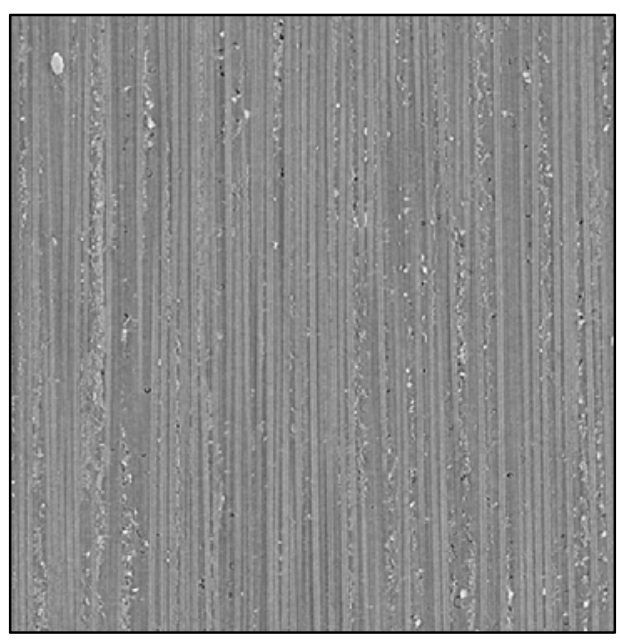

$\mathrm{SiO}_{2} 400$ nm, 10 wt. \% (slice 480)

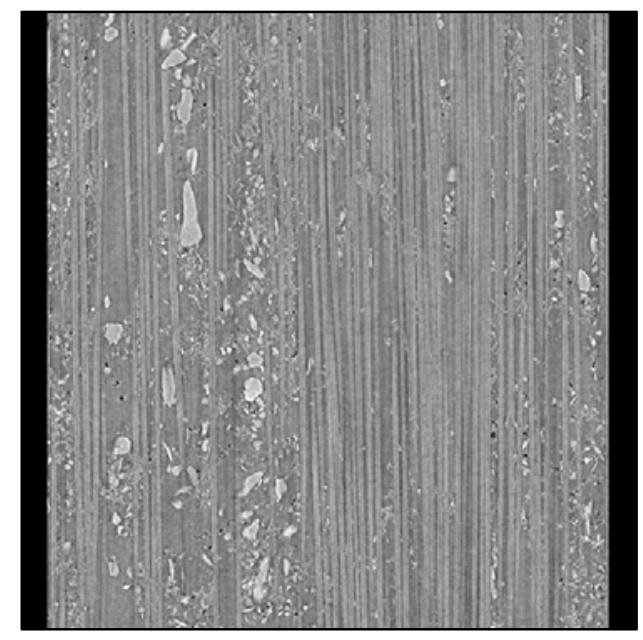

MgO 300 nm, 10 wt. \% (slice 320)

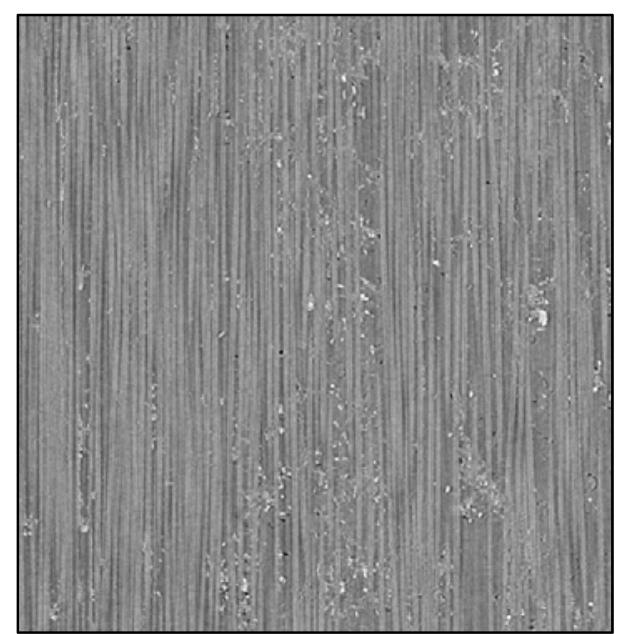

$\mathrm{SiO}_{2} 400$ nm, 7.5 wt. \% (slice 562)

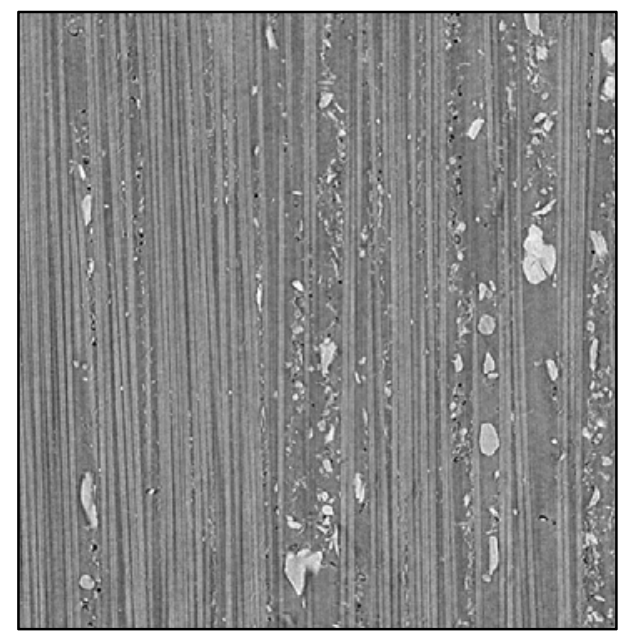

MgO 300 nm, 7.5 wt. \% (slice 425)

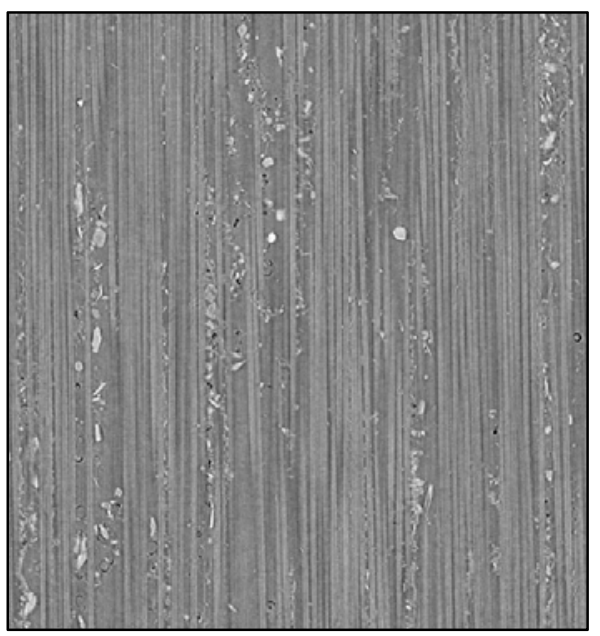

MgO 600 nm, 7.5 wt. \% (slice 370) 
Journal of Composite Materials (2020)

DOI: $10.1177 / 0021998320966388$

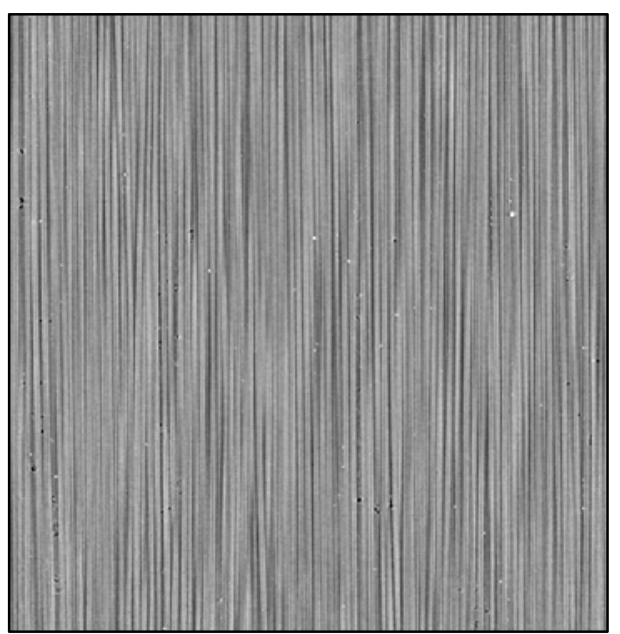

TiC 800 nm, 0.25 wt. \% (slice 556)

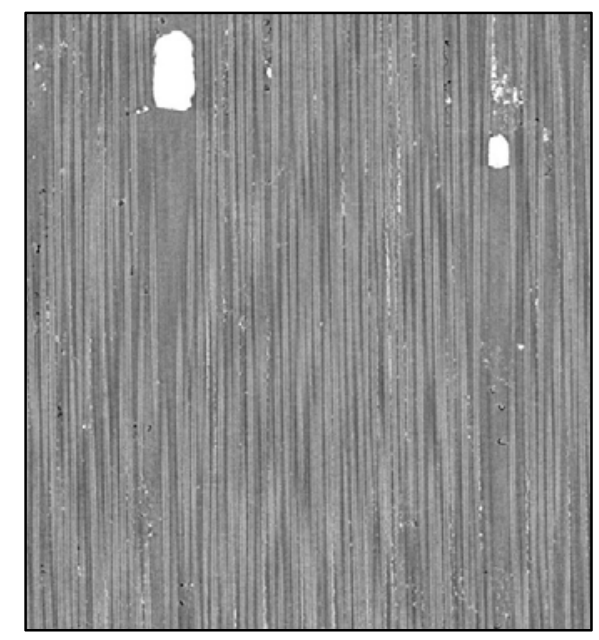

$\mathrm{TiO}_{2} 300$ nm, 5 wt. \% (slice 656)

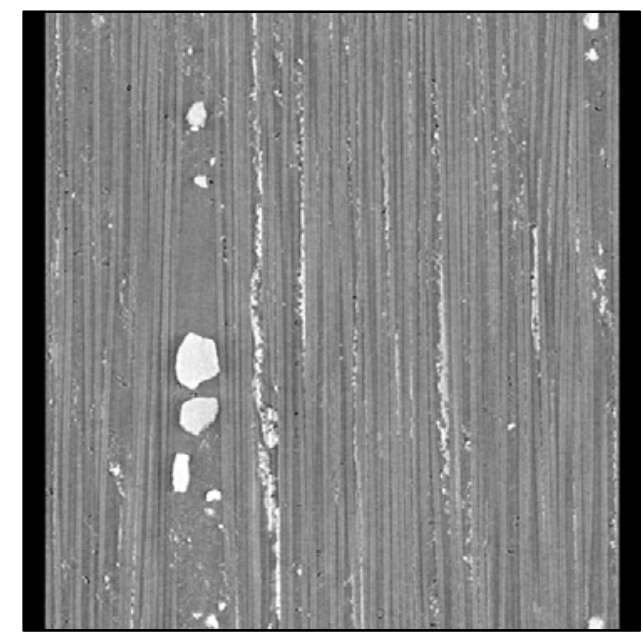

$\mathrm{TiO}_{2} 300$ nm, 10 wt. \% (slice 343)

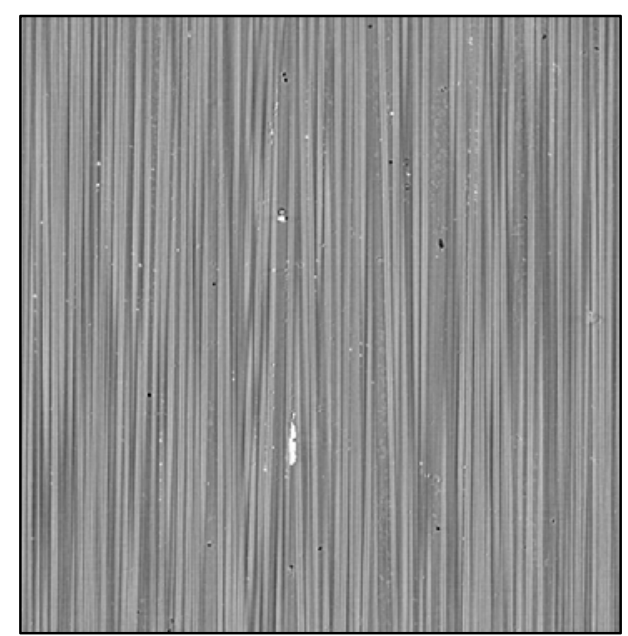

TiC 800 nm, 0.5 wt. \% (slice 451)

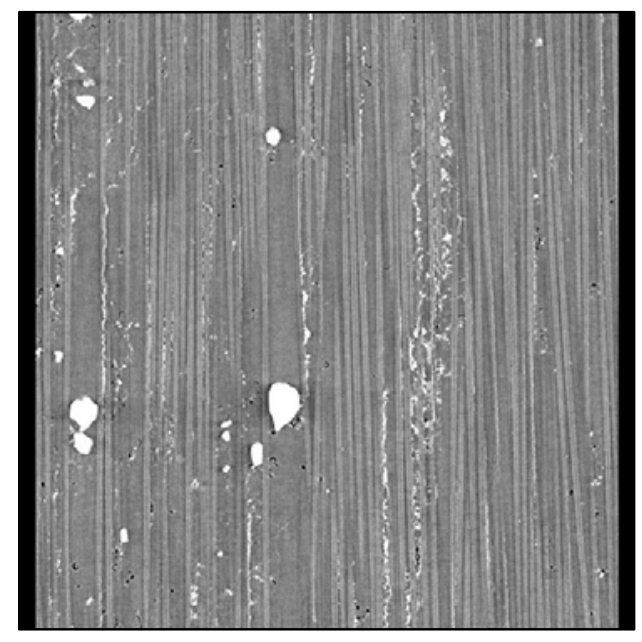

$\mathrm{TiO}_{2} 300$ nm, 7.5 wt. \% (slice 631)

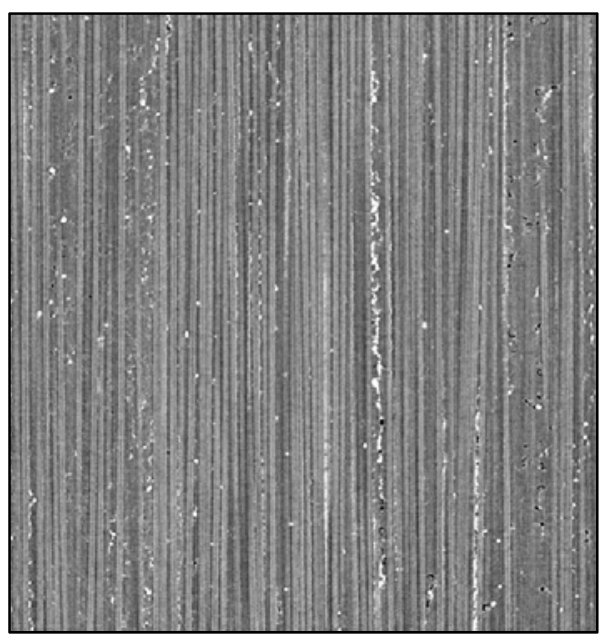

$\mathrm{TiO}_{2} 500$ nm, 7.5 wt. \% (slice 615) 
Journal of Composite Materials (2020)

DOI: $10.1177 / 0021998320966388$

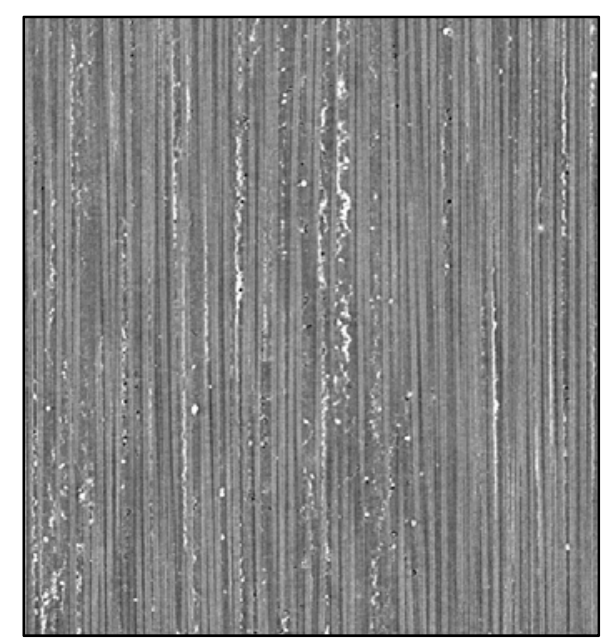

$\mathrm{TiO}_{2} 500$ nm, 10 wt. \% (slice 355)

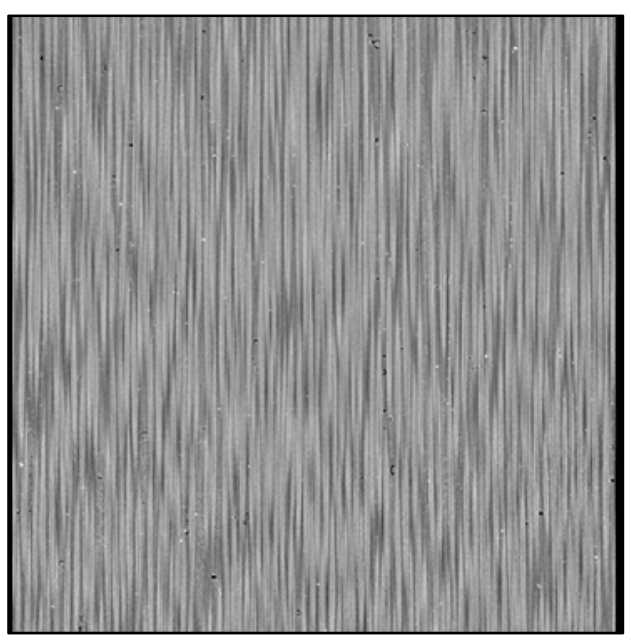

$\mathrm{BaTiO}_{3} 400$ nm, 0.25 wt. \% (slice 458)

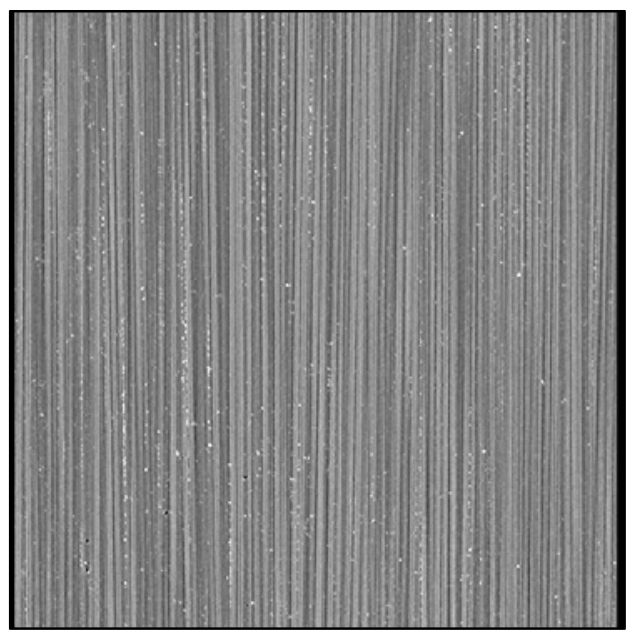

$\mathrm{BaTiO}_{3} 400$ nm, 1 wt. \% (slice 470)

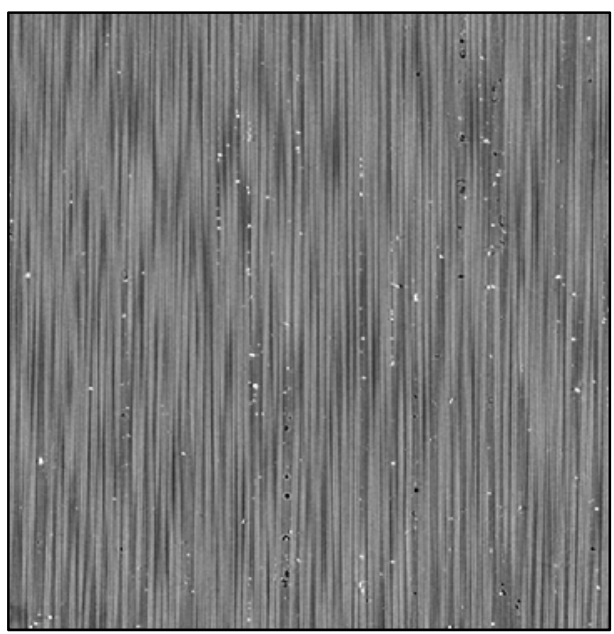

$\mathrm{BaCO}_{3} 800$ nm, 0.5 wt. \% (slice 507)

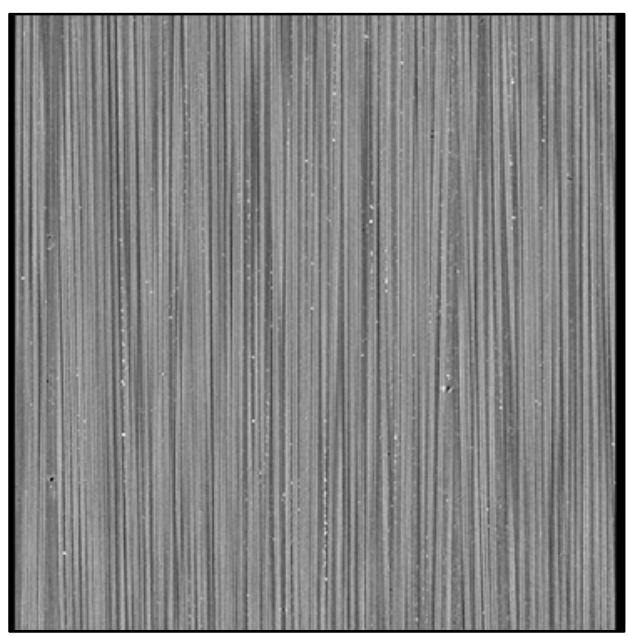

$\mathrm{BaTiO}_{3} 400$ nm, 0.5 wt. \% (slice 441)

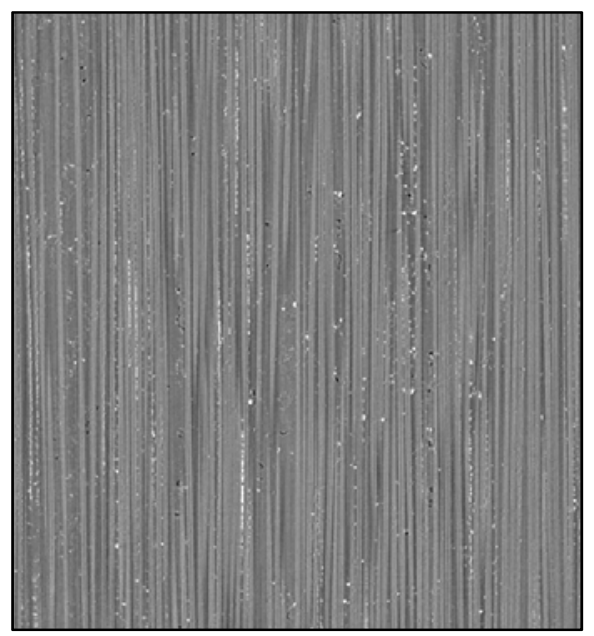

$\mathrm{BaTiO}_{3} 400$ nm, 2 wt. \% (slice 346) 
Journal of Composite Materials (2020)

DOI: $10.1177 / 0021998320966388$

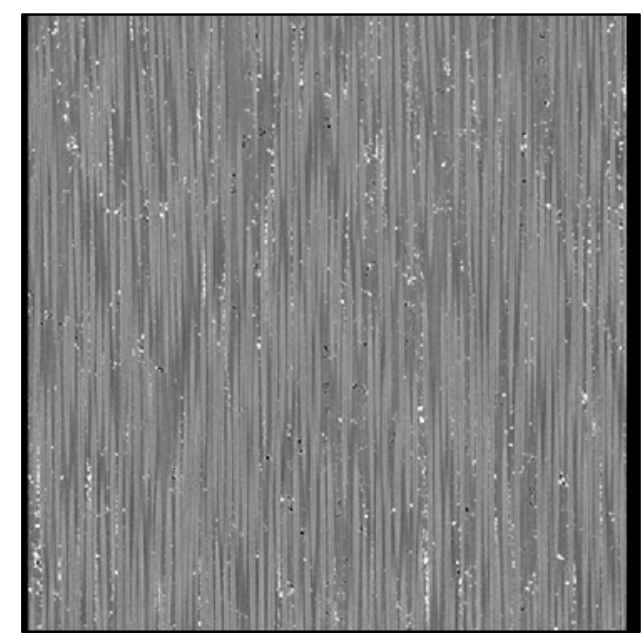

$\mathrm{BaTiO}_{3} 400$ nm, 3 wt. \% (slice 452)

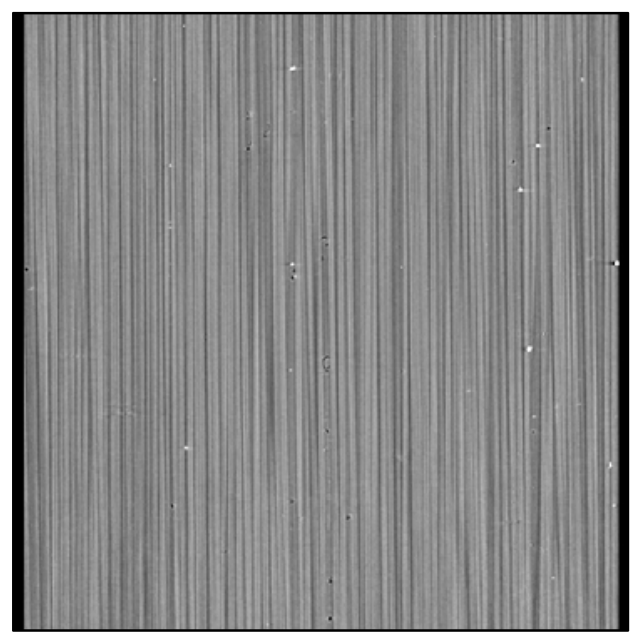

$\mathrm{Cu} 580$ nm, 0.25 wt. \% (slice 398)

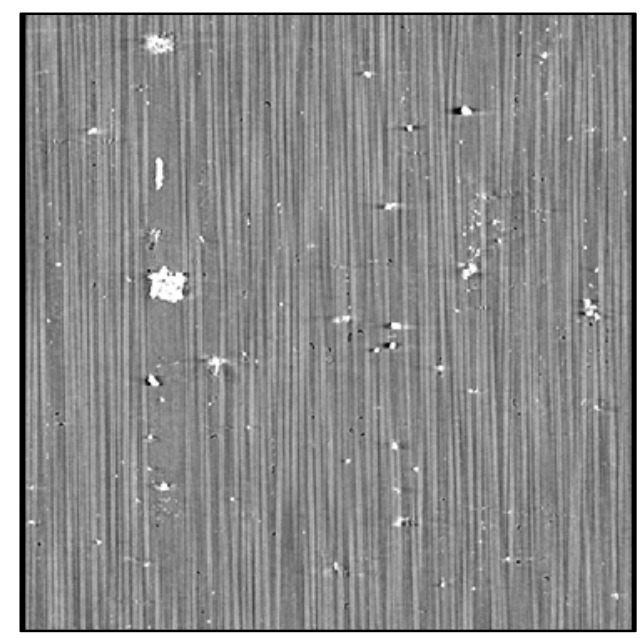

Cu 580 nm, 1 wt. \% (slice 452)

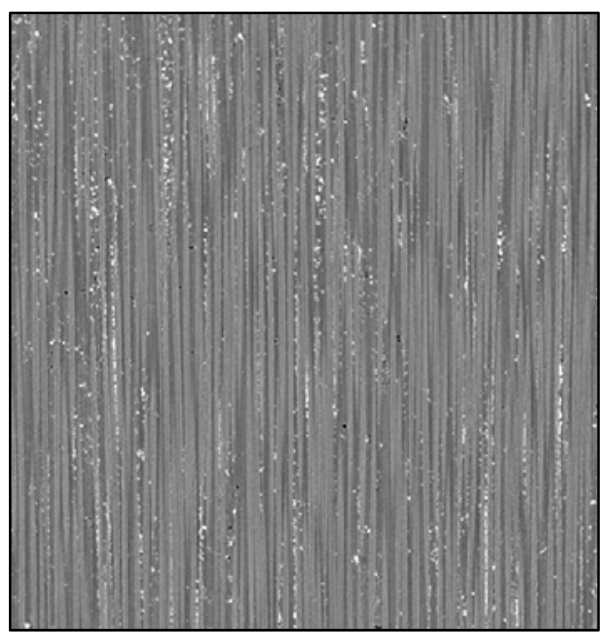

$\mathrm{BaTiO}_{3} 400$ nm, 4 wt. \% (slice 394)

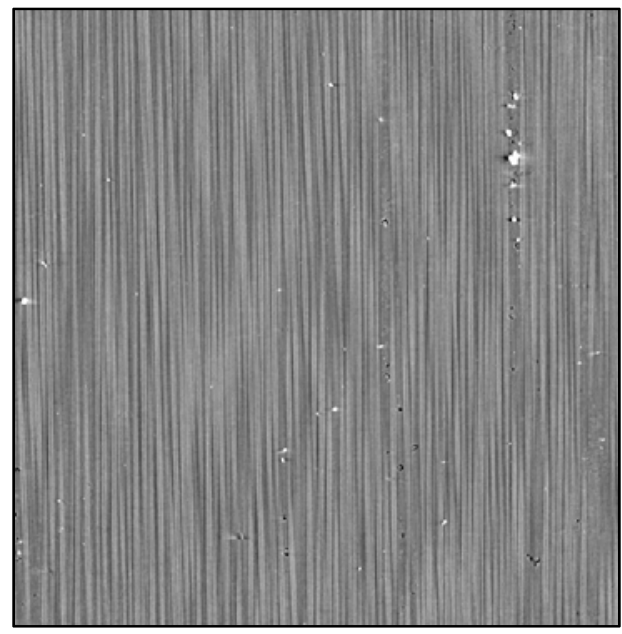

Cu 580 nm, 0.5 wt. \% (slice 452)

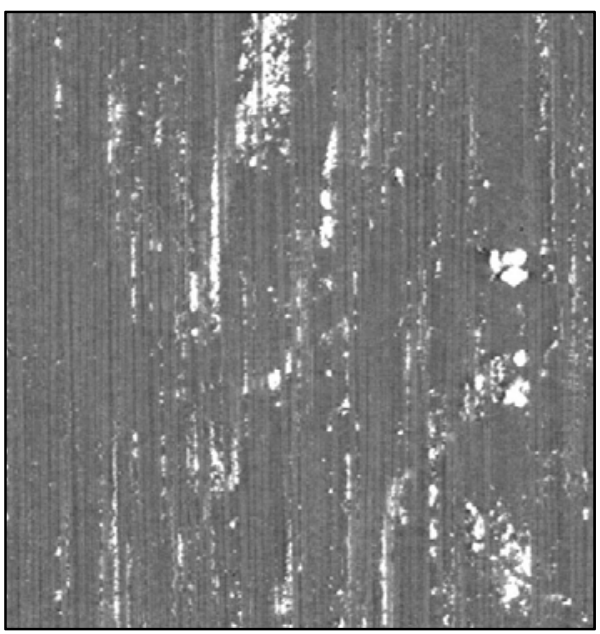

$\mathrm{Bi}_{2} \mathrm{O}_{3} 800$ nm, 10 wt. \% (slice 487) 


\section{Appendix B - Microstructural analysis}

\begin{tabular}{|c|c|c|}
\hline $\begin{array}{c}\text { Fiducial } \\
\text { marker system }\end{array}$ & Ranking & Detailed list of comments \\
\hline $\mathrm{Al}$ & $\checkmark \checkmark \checkmark$ & $\begin{array}{l}\text { - The } 800 \mathrm{~nm} \text { aluminium particles are identifiable from the lowest concentration } \\
\text { used of } 0.25 \mathrm{wt} \text { \%, albeit with a sparse spatial distribution. } \\
\text { - Increasing the concentration to } 1 \mathrm{wt} \text {. \% results in a marginal improvement. } \\
\text { The spatial distribution is improved at a concentration of } 5 \mathrm{wt} . \% \text { and } 10 \mathrm{wt} . \% \text {, } \\
\text { respectively. } \\
\text { At a concentration of } 10 \mathrm{wt} \text { \%, aluminium is deposited between individual fibres, } \\
\text { forming the desired 'strips' of fiducial markers in the fibre direction, without } \\
\text { introducing gross microstructural anomalies. This appears to satisfy the imaging } \\
\text { requirements for local DVC analyses. } \\
\text { The highest concentration investigated of } 15 \mathrm{wt} . \% \text { causes particles to clump } \\
\text { significantly, forming heterogeneous 'bands' of fiducial markers along the fibre } \\
\text { direction, and subsequently generating substantial disruption in the separation and } \\
\text { packing of fibres at tow-level. }\end{array}$ \\
\hline $\mathrm{Al}_{2} \mathrm{O}_{3}$ & $\checkmark$ & $\begin{array}{l}\text { - The } 300 \mathrm{~nm} \text { and } 500 \mathrm{~nm} \text { aluminium oxide particle sizes yield a relatively sparse } \\
\text { spatial distribution at a concentration of } 7.5 \mathrm{wt} . \% \text { (e.g. compared to the } 800 \mathrm{~nm} \\
\text { aluminium particles at a concentration of } 10 \mathrm{wt} \text {. \%). } \\
\text { The homogeneity of the spatial distribution does not improve, for either particle } \\
\text { size, if the concentration is increased to } 10 \mathrm{wt} . \% \text {; on the contrary, the prominence } \\
\text { of particle 'bands' increases, in conjunction with a greater agglomerate presence. } \\
\text { Agglomerates represent the heaviest form of local particle clumping detected, } \\
\text { with the accompanying microstructural disruption being considerably higher than } \\
\text { that caused by the particle 'bands'. } \\
\text { The } 300 \mathrm{~nm} \text { system appears to yield a slightly superior particle deposition } \\
\text { between the individual carbon-filaments compared to the } 500 \mathrm{~nm} \text { counterpart. } \\
\text { This may be attributed to less filtering as the fibre tow was drawn through the } \\
\text { metering die, and thus as a superior deposition of aluminium oxide during } \\
\text { manufacture. } \\
\text { At the largest aluminium oxide particle size of } 800 \text { nm investigated, the spatial } \\
\text { distribution is sparse compared to the } 300 \mathrm{~nm} \text { and } 500 \mathrm{~nm} \text { counterpart (applicable } \\
\text { to both concentrations investigated of } 7.5 \mathrm{wt} . \% \text { and } 10 \text { wt. \%, respectively). } \\
\text { The } 800 \mathrm{~nm} \text { system appears not to be associated with the formation of } \\
\text { agglomerates, but rather with the presence of individual particles of evidently } \\
\text { larger size, if compared alongside the mean stated by the manufacturer. In turn, } \\
\text { this may be explained through a large variability in particle size for this system. } \\
\text { At a concentration of } 10 \text { wt. \%, the spatial distribution of the } 800 \mathrm{~nm} \text { aluminium } \\
\text { oxide particles is sparse compared to the } 800 \mathrm{~nm} \text { aluminium system. }\end{array}$ \\
\hline $\mathrm{SiC}$ & $\checkmark$ & $\begin{array}{l}\text { - At a concentration of } 0.25 \mathrm{wt} . \% \text { and } 0.5 \mathrm{wt} . \% \text {, respectively, the spatial } \\
\text { distribution of the } 600 \mathrm{~nm} \text { silicon carbide system is sparse. This is similar to the } \\
\text { other materials doped with very low particle concentrations }(<1 \mathrm{wt.} \%) \text {. } \\
\text { Increasing the concentration to } 15 \mathrm{wt} \text {. \% results in a microstructure abundant with } \\
\text { gross microstructural anomalies (both particle 'bands' and agglomerates), which } \\
\text { fails to satisfy the established considerations. } \\
\text { Compared to the more attenuating compounds (e.g. TiC, BaTiOz), the imaging } \\
\text { contrast obtained between the silicon carbide particles and the carbon-filaments is } \\
\text { noticeably less - this is consistent with the attenuation profiles shown in Fig. } 1 \text {. }\end{array}$ \\
\hline $\mathrm{SiO}_{2}$ & $\checkmark \checkmark$ & 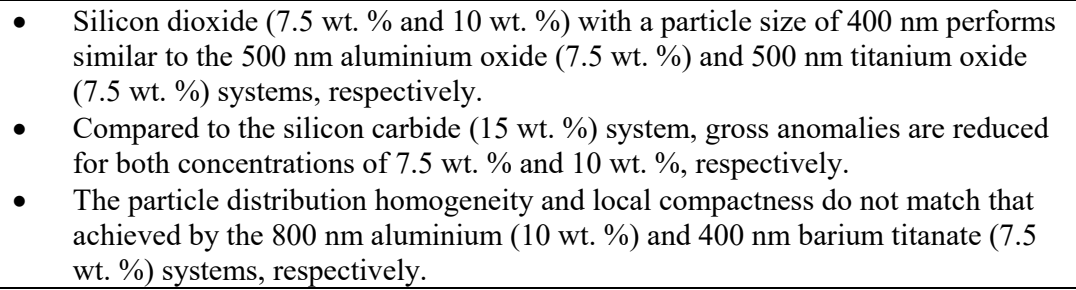 \\
\hline
\end{tabular}




\begin{tabular}{|c|c|c|}
\hline $\mathrm{MgO}$ & $\checkmark$ & $\begin{array}{l}\text { Doping the matrix with } 300 \mathrm{~nm} \text { magnesium oxide particles at a concentration } 7.5 \\
\% \text { and } 10 \% \text {, respectively, results in a cured material with the highest departure } \\
\text { from the established considerations. } \\
\text { The microstructure is characterized by an abundance of agglomerates, particularly } \\
\text { at the higher concentrations. } \\
\text { The magnesium oxide agglomerates have a 'crystal-like' appearance, } \\
\text { differentiated by sharp edges from the other compositions examined. It may be } \\
\text { envisaged that under applied load, these sharp edges would act as stress raisers } \\
\text { (concentrations), promoting extensive matrix microcracking. } \\
\text { In conjunction with the substantial disruption in the separation and packing of } \\
\text { fibres at tow-level, the doping of the matrix with magnesium oxide may be } \\
\text { expected to significantly reduce the overall mechanical performance of the } \\
\text { composite. } \\
\text { Doubling the particle size of the magnesium oxide (i.e. } 600 \mathrm{~nm} \text { ) for a } \\
\text { concentration of } 7.5 \text { wt. \% results in no substantial improvements with respect to } \\
\text { the } 300 \mathrm{~nm} \text { counterpart at the equivalent concentration. }\end{array}$ \\
\hline $\mathrm{TiC}$ & $\checkmark$ & $\begin{array}{l}\text { - At a size of } 800 \mathrm{~nm} \text {, titanium carbide particles are identifiable despite the very } \\
\text { low concentrations investigated }(0.25 \mathrm{wt} . \% \text { and } 0.5 \mathrm{wt} . \%) \text {. } \\
\text { The imaging requirements for local DVC analyses are not satisfied at these } \\
\text { concentrations. } \\
\text { Agglomerates are identified within the visible region, indicating that the system is } \\
\text { generally prone to early-onset clumping. } \\
\text { Given the very low particle concentrations, it is also conceivable that the large } \\
\text { agglomerates pre-existed in the powder, and are thus not associated with the } \\
\text { manufacturing process. }\end{array}$ \\
\hline $\mathrm{TiO}_{2}$ & $\checkmark \checkmark$ & $\begin{array}{l}\text { - The doping of the matrix with } 300 \mathrm{~nm} \text { titanium oxide ( } 5 \mathrm{wt} . \%, 7.5 \mathrm{wt} . \% \text { and } 10 \\
\text { wt. \%) yields a marginal improvement compared to the magnesium oxide systems } \\
\text { ( } 300 \mathrm{~nm} \text { and } 600 \mathrm{~nm} \text {, respectively). } \\
\text { - Similarly, compared to the magnesium oxide counterpart, agglomerates no longer } \\
\text { have sharp edges and the overall abundance is slightly reduced within the } \\
\text { microstructure. However, the CFRP is mainly characterized by lighter forms of } \\
\text { clumping (i.e. heterogeneous 'bands' of fiducial markers). } \\
\text { As in the case of aluminium ( } 800 \mathrm{~nm}, 15 \mathrm{wt} \text {. \%), these particle 'bands' } \\
\text { significantly affect the separation and packing of fibres. } \\
\text { The homogeneity of the spatial distribution appears to decrease with increasing } \\
\text { particle concentration - indicating that the titanium oxide system is prone to } \\
\text { clumping at the higher concentrations used. } \\
\text { The homogeneity of the spatial distribution is improved considerably by } \\
\text { increasing the particle size to } 500 \mathrm{~nm} \text {, at a concentration of } 7.5 \text { wt. \% (this is } \\
\text { contrary to the magnesium oxide system, which did not respond substantially to a } \\
\text { change in particle size). } \\
\text { Increasing the concentration to } 10 \mathrm{wt} \text {. \% for the } 500 \mathrm{~nm} \text { system, results in a } \\
\text { decrease in the distribution's homogeneity, however, still superior to the } 300 \mathrm{~nm} \\
\text { counterpart system at the equivalent concentration. } \\
\text { Overall, the particle distribution does not match that of barium titanate, } \\
\text { particularly in terms of inter-fibre deposition. }\end{array}$ \\
\hline $\mathrm{BaCO}_{3}$ & $\checkmark$ & $\begin{array}{l}\text { - At a concentration of } 0.5 \mathrm{wt} . \% \text {, the } 800 \mathrm{~nm} \text { barium carbonate system yields } \\
\text { similar results to those obtained by the titanium carbide system. } \\
\text { A marginally improved particle distribution homogeneity may be observed } \\
\text { compared to the titanium carbide system. }\end{array}$ \\
\hline
\end{tabular}




\begin{tabular}{|c|c|c|}
\hline $\mathrm{BaTiO}_{3}$ & $\checkmark \checkmark \checkmark$ & $\begin{array}{l}\text { - At a size of } 400 \mathrm{~nm} \text {, barium titanate exhibits a progressive improvement in } \\
\text { particle distribution homogeneity with increasing concentration: } 0.25 \mathrm{wt} . \%, 0.5 \\
\text { wt. } \%, 1 \mathrm{wt} . \%, 2 \mathrm{wt} . \%, 3 \mathrm{wt} . \%, 4 \mathrm{wt} . \% \text {, and } 7.5 \mathrm{wt} . \% \text {. } \\
\text { The particle distribution remains homogenous throughout the higher } \\
\text { concentrations, with the desirable particle compactness for local DVC analyses } \\
\text { achieved at the highest concentration of } 7.5 \mathrm{wt} \text {. \%. } \\
\text { The } 7.5 \mathrm{wt} . \% \text { system also presents a reduced level of microstructural anomalies, } \\
\text { with instances being isolated and generally limited to less than } \sim 10 \mu \mathrm{m} \text { within the } \\
\text { visible region. In this respect, it is similar to the aluminium } 800 \mathrm{~nm} \text { system ( } 10 \\
\text { wt. \%). } \\
\text { Even though, at a concentration of } 7.5 \mathrm{wt} . \% \text {, the microstructure is not completely } \\
\text { free of particle 'bands', a desirable compromise is achieved between the local } \\
\text { deposition of particles in the fibre direction and any potential mechanical property } \\
\text { detriment. } \\
\text { Also, the barium titanate system does not appear to be prone to agglomerate } \\
\text { formation. }\end{array}$ \\
\hline $\mathrm{Cu}$ & $\checkmark$ & $\begin{array}{l}\text { - At a concentration of } 0.25 \mathrm{wt} . \% \text {, the } 580 \mathrm{~nm} \text { copper particles are well- } \\
\text { recognizable, despite a sparse spatial distribution. } \\
\text { The spatial distribution is somewhat improved at a concentration of } 0.5 \mathrm{wt} . \% \text { and } \\
1 \mathrm{wt} \% \text {, respectively, notwithstanding that copper appears to be particularly } \\
\text { prone to agglomerate development with increasing concentration, and thus a } \\
\text { departure from a homogenous distribution within the composite bulk. } \\
\text { This system is overly attenuating (see Fig. 1), such that at the energies available, } \\
\text { it promoted imaging artefacts, visible as streak patterns surrounding the fiducial } \\
\text { markers. As with any artefact, it is not desirable for DVC analyses as it may lead } \\
\text { to an increased predisposition to noise. }\end{array}$ \\
\hline $\mathrm{Bi}_{2} \mathrm{O}_{3}$ & $\checkmark$ & $\begin{array}{l}\text { - At a size of } 800 \mathrm{~nm} \text { and concentration of } 10 \mathrm{wt} . \% \text {, the spatial distribution } \\
\text { obtained by doping the matrix with bismuth oxide is sparse. } \\
\text { A combination of both particle 'bands' and agglomerates are observed along the } \\
\text { fibre direction, causing substantial disruption in the local fibre packing at tow- } \\
\text { level. } \\
\text { - Similar to copper, bismuth oxide is too attenuating compared to carbon at the } \\
\text { beam energies available in the present work. }\end{array}$ \\
\hline
\end{tabular}

Table 7 -Detailed comments complementing the ranking system in Table 5. 


\section{References}

[1] Y. Swolfs, H. Morton, A. E. Scott, L. Gorbatikh, P. A. S. Reed, I. Sinclair, S. M. Spearing and I. Verpoest, "Synchrotron radiation computed tomography for experimental validation of a tensile strength model for unidirectional fibre-reinforced composites," Composites Part $A$, vol. 77, pp. 106-113, 2015.

[2] J. Bohse, "Acoustic emission characteristics of micro-failure processes in polymer blends and composites," Composites Science and Technology, vol. 60, no. 8, pp. 1213-1226, 2000.

[3] N. De Greef, L. Gorbatikh, A. Godara, L. Mezzo, S. V. Lomov and I. Verpoest, "The effect of carbon nanotubes on the damage development in carbon fiber/epoxy composites," Carbon, vol. 49, no. 14, pp. 4650-4664, 2011.

[4] A. E. Scott, M. N. Mavrogordato, P. Wright, I. Sinclair and S. M. Spearing, "In situ fibre fracture measurement in carbon-epoxy laminates using high resolution computed tomography," Composites Science and Technology, vol. 71, no. 12, pp. 1471-1477, 2011.

[5] A. E. Scott, I. Sinclair, S. M. Spearing, A. Thionnet and A. R. Bunsell, "Damage accumulation in a carbon/epoxy composite: Comparison between a multiscale model and computed tomography experimental results," Composites Part A, vol. 43, no. 9, pp. 1514-1522, 2012.

[6] S. Blassiau, A. R. Bunsell and A. Thionnet, "Damage accumulation processes and life prediction in unidirectional composites," Proceedings of the Royal Society A, vol. 463, no. 2080, pp. 1135-1152, 2007.

[7] E. Schöberl, M. N. Mavrogordato, I. Sinclair and S. M. Spearing, "Fibre-direction strain measurement in a composite ply under pure bending using digital volume correlation and microfocus computed tomography," Journal of Composite Materials, vol. 54, no. 14, pp. 1889-1911, 2020.

[8] E. Schöberl, C. Breite, A. Melnikov, Y. Swolfs, M. N. Mavrogordato, I. Sinclair and S. M. Spearing, "Fibre-direction strain measurement in a composite ply under quasi-static tensile loading using digital volume correlation and in situ synchrotron radiation computed tomography," Composites Part A, vol. 137, no. 105935, 2020.

[9] Y. Swolfs, I. Verpoest and L. Gorbatikh, "A review of input data and modelling assumptions in longitudinal strength models for unidirectional fibre-reinforced composites," Composite Structures, vol. 150, pp. 153-172, 2016.

[10] J. Watanabe, F. Tanaka, H. Okuda and T. Okabe, "Tensile strength distribution of carbon fibers at short gauge lengths," Advanced Composite Materials, vol. 23, no. 5-6, pp. 535-550, 2014. 


\section{Journal of Composite Materials (2020) \\ DOI: $10.1177 / 0021998320966388$}

[11] S. L. Phoenix and I. J. Beyerlein, Comprehensive composite materials. Chapter 1.19-Statistical strength theory for fibrous composite materials, 1st ed., vol. 1, A. Kelly and C. Zweben, Eds., Oxford, UK: Pergamon Press, 2000, pp. 559-639.

[12] B. W. Rosen, "Tensile failure of fibrous composites," AIAA Journal, vol. 2, no. 11, pp. 1985-1991, 1964.

[13] Y. Swolfs, L. Gorbatikh, V. Romanov, S. Orlova, S. V. Lomov and I. Verpoest, "Stress concentrations in an impregnated fibre bundle with random fibre packing," Composites Science and Technology, vol. 74, pp. 113-120, 2013.

[14] Y. Swolfs, R. M. McMeeking, I. Verpoest and L. Gorbatikh, "Matrix cracks around fibre breaks and their effect on stress redistribution and failure development in unidirectional composites," Composites Science and Technology, vol. 108, pp. 16-22, 2015.

[15] M. R. Nedele and M. R. Wisnom, "Three-dimensional finite element analysis of the stress concentration at a single fibre break," Composites Science and Technology, vol. 51, no. 4, pp. 517524, 1994.

[16] M. R. Nedele and M. R. Wisnom, "Stress concentration factors around a broken fibre in a unidirectional carbon fibre-reinforced epoxy," Composites, vol. 25, no. 7, pp. 549-557, 1994.

[17] A. Thionnet, H. Y. Chou and A. R. Bunsell, "Fibre break processes in unidirectional composites," Composites Part A, vol. 65, pp. 148-160, 2014.

[18] Y. Swolfs, I. Verpoest and L. Gorbatikh, "Issues in strength models for unidirectional fibrereinforced composites related to Weibull distributions, fibre packings and boundary effects," Composites Science and Technology, vol. 114, pp. 42-49, 2015.

[19] S. C. Garcea, I. Sinclair, S. M. Spearing and P. J. Withers, "Mapping fibre failure in situ in carbon fibre reinforced polymers by fast synchrotron X-ray computed tomography," Composites Science and Technology, vol. 149, pp. 81-89, 2017.

[20] S. Rosini, M. N. Mavrogordato, O. Egorova, E. S. Matthews, S. E. Jackson, S. M. Spearing and I. Sinclair, "In situ statistical measurement of local morphology in carbon-epoxy composites using synchrotron X-ray computed tomography," Composites Part A, vol. 125, pp. 1-14, 2019.

[21] K. L. Pickering, M. G. Bader and A. C. Kimber, "Damage accumulation during the failure of uniaxial carbon fibre composites," Composites Part A, vol. 29, no. 4, pp. 435-441, 1998.

[22] N. J. Pagano, "On the micromechanical failure modes in a class of ideal brittle matrix composites. Part 1 - Coated-fiber composites," Composites Part B, vol. 29, no. 2, pp. 93-119, 1998.

[23] S. C. Garcea, Y. Wang and P. J. Withers, "X-ray computed tomography of polymer composites," Composites Science and Technology, vol. 156, pp. 305-319, 2018. 


\section{Journal of Composite Materials (2020)}

DOI: $10.1177 / 0021998320966388$

[24] J. M. Lifshitz and A. Rotem, "Time-dependent longitudinal strength of unidirectional fibrous composites," Fibre Science and Technology, vol. 3, no. 1, pp. 1-20, 1970.

[25] A. R. Bunsell and A. Thionnet, "Life prediction for carbon fibre filament wound composite structures," Philosophical Magazine, vol. 90, no. 31-32, pp. 4129-4146, 2010.

[26] A. R. Bunsell and A. Thionnet, "Failure processes governing long term reliability of carbon fibre composites structures," Composites and Nanostructures, vol. 7, no. 4, pp. 216-224, 2015.

[27] A. J. Moffat, P. Wright, J.-Y. Buffiere, I. Sinclair and S. M. Spearing, "Micromechanisms of damage in $0^{\circ}$ splits in a [90/0]s composite material using synchrotron radiation computed tomography," Scripta Materialia, vol. 59, no. 10, pp. 1043-1046, 2008.

[28] P. Wright, A. J. Moffat, I. Sinclair and S. M. Spearing, "High resolution tomographic imaging and modelling of notch tip damage in a laminated composite," Composites Science and Technology, vol. 70, no. 10, pp. 1444-1452, 2010.

[29] A. Bunsell, L. Gorbatikh, H. Morton, S. Pimenta, I. Sinclair, S. M. Spearing, Y. Swolfs and A. Thionnet, "Benchmarking of strength models for unidirectional composites under longitudinal tension," Composites Part A, vol. 111, pp. 138-150, 2018.

[30] Y. Huang and R. J. Young, "Analysis of the fragmentation test for carbon-fibre/epoxy model composites by means of Raman spectroscopy," Composites Science and Technology, vol. 52, no. 4, pp. 505-517, 1994.

[31] Y. Huang and R. J. Young, "Interfacial behaviour in high temperature cured carbon fibre/epoxy resin model composite," Composites, vol. 26, no. 8, pp. 541-550, 1995.

[32] P. W. J. van den Heuvel, T. Peijs and R. J. Young, "Analysis of stress concentrations in multi-fibre microcomposites by means of Raman spectroscopy," Journal of Materials Science Letters, vol. 15, no. 21, pp. 1908-1911, 1996.

[33] P. W. J. van den Heuvel, T. Peijs and R. J. Young, "Failure phenomena in two-dimensional multifibre microcomposites. Part 4-A Raman spectroscopic study on the influence of the matrix yield stress on stress concentrations," Composites Part A, vol. 31, no. 2, pp. 165-171, 2000.

[34] B. Pan, K. Qian, H. Xie and A. Asundi, "Two-dimensional digital image correlation for in-plane displacement and strain measurement: A review," Measurement Science and Technology, vol. 20, no. 6, pp. 1-17, 2009.

[35] B. K. Bay, T. S. Smith, D. P. Fyhrie and M. Saad, "Digital volume correlation: Three-dimensional strain mapping using X-ray tomography," Experimental Mechanics, vol. 39, no. 3, pp. 217-226, 1999. 


\section{Journal of Composite Materials (2020) \\ DOI: $10.1177 / 0021998320966388$}

[36] J. Adam, M. Klinkmüller, G. Schreurs and B. Wieneke, "Quantitative 3D strain analysis in analogue experiments simulating tectonic deformation: Integration of X-ray computed tomography and digital volume correlation techniques," Journal of Structural Geology, vol. 55, pp. 127-149, 2013.

[37] F. Xu, "Quantitative characterization of deformation and damage process by digital volume correlation: A review," Theoretical \& Applied Mechanics Letters, vol. 8, no. 2, pp. 83-96, 2018.

[38] B. K. Bay, "Methods and applications of digital volume correlation," Journal of Strain Analysis for Engineering Design, vol. 43, no. 8, pp. 745-760, 2008.

[39] L. Wang, N. Limodin, A. El Bartali, J.-F. Witz, R. Seghir, J.-Y. Buffiere and E. Charkaluk, "Influence of pores on crack initiation in monotonic tensile and cyclicloadings in lost foam casting A319 alloy by using 3D in-situ analysis," Materials Science \& Engineering A, vol. 673, pp. 362-372, 2016.

[40] G. Borstnar, F. Gillard, M. N. Mavrogordato, I. Sinclair and S. M. Spearing, "Three-dimensional deformation mapping of Mode I interlaminar crack extension in particle-toughened interlayers," Acta Materialia, vol. 103, pp. 63-70, 2015.

[41] R. Brault, A. Germaneau, J. C. Dupré, P. Doumalin, S. Mistou and M. Fazzini, "In-situ analysis of laminated composite materials by $\mathrm{X}$-ray micro-computed tomography and digital volume correlation," Experimental Mechanics, vol. 53, pp. 1143-1151, 2013.

[42] L. M. McGrath, R. S. Parnas, S. H. King, J. L. Schroeder, D. A. Fischer and J. L. Lenhart, "Investigation of the thermal, mechanical, and fracture properties of alumina-epoxy composites," Polymer, vol. 49, no. 4, pp. 999-1014, 2008.

[43] C. Chen, R. S. Justice, D. W. Schaefer and J. W. Baur, "Highly dispersed nanosilica-epoxy resins with enhanced mechanical properties," Polymer, vol. 49, no. 17, pp. 3805-3815, 2008.

[44] Toray Industries Inc., Toray Composite Materials, Tokyo, Japan, 2019.

[45] Sicomin, Epoxy Systems, Châteauneuf-les-Martigues, France, 2018.

[46] US Research Nanomaterials Inc., Micron Powders, Houston, TX, USA, 2019.

[47] E. N. Landis and D. T. Keane, "X-ray microtomography," Materials Characterization, vol. 61, no. 12, pp. 1305-1316, 2010.

[48] E. Maire, J.-Y. Buffière, L. Salvo, J. J. Blandin, W. Ludwig and J. M. Létang, "On the application of Xray microtomography in the field of materials science," Advanced Engineering Materials, vol. 3, no. 8, pp. 539-546, 2001.

[49] National Institute of Standards and Technology (NIST), "X-Ray Mass Attenuation Coefficients," Physical Measurement Laboratory (PML), 0106 2017. [Online]. Available: https://www.nist.gov/pml/x-ray-mass-attenuation-coefficients.

[50] Ultrawave Ltd., U100/U100H Ultrasonic Cleaning Bath, Cardiff, UK, 2017. 
[51] 3M Company, Epoxy Adhesive, Maplewood, MN, USA, 2019.

[52] Deben Ltd., CT5000 5kN in-situ tensile stage for $\mu$ XCT applications, Woolpit, Suffolk, UK, 2019.

[53] Carl Zeiss AG, Xradia 510 Versa, Oberkochen, Germany, 2018.

[54] J. Schindelin, I. Arganda-Carreras, E. Frise, V. Kaynig, M. Longair, T. Pietzsch, S. Preibisch, C. Rueden, S. Saalfeld, B. Schmid, J.-Y. Tinevez, D. J. White, V. Hartenstein, K. Eliceiri, P. Tomancak and A. Cardona, "Fiji: An open-source platform for biological-image analysis," Nature Methods, vol. 9, pp. 676-682, 2012.

[55] C. Breite, L. Gorbatikh, Y. Swolfs, M. Alves, S. Pimenta, E. Schöberl, M. Mavrogordato, I. Sinclair, S. M. Spearing, J. Rojek, A. Thionnet and A. Bunsell, "Benchmarking exercise II for longitudinal strength models of unidirectional composites - Instructions for participants," Marie SkłodowskaCurie European Training Network FiBreMoD, Leuven, Belgium, 2018.

[56] M. A. Suhot and A. R. Chambers, "The effect of voids on the flexural fatigue performance of unidirectional carbon fibre composites," in 16th International Conference on Composite Materials, Kyoto, Japan, 2007.

[57] A. E. Scott, I. Sinclair, S. M. Spearing, M. N. Mavrogordato and W. Hepples, "Influence of voids on damage mechanisms in carbon/epoxy composites determined via high resolution computed tomography," Composites Science and Technology, vol. 90, pp. 147-153, 2014.

[58] F. Tanaka, T. Okabe, H. Okuda, I. A. Kinloch and R. J. Young, "Factors controlling the strength of carbon fibres in tension," Composites Part A, vol. 57, pp. 88-94, 2014.

[59] T. Okabe and N. Takeda, "Size effect on tensile strength of unidirectional CFRP composites experiment and simulation," Composites Science and Technology, vol. 62, no. 15, pp. 2053-2064, 2002.

[60] A. E. Scott, "Analysis of a hybrid composite pressure vessel using multi-scale computed tomography techniques - PhD Thesis," University of Southampton, Southampton, UK, 2011.

[61] H. Morton, "3D Imaging of the tensile failure mechanisms of carbon fibre composites - PhD Thesis," University of Southampton, Southampton, UK, 2014. 